\title{
TRAJETÓRIAS POLÍTICAS E CHANCES ELEITORAIS: ANALISANDO O “GÊNERO” DAS CANDIDATURAS EM 2010
}

\author{
Clara Araújo
}

\author{
Doriam Borges
}

\begin{abstract}
RESUMO
O artigo apresenta os resultados principais de um survey com candidatos ao cargo de Deputado Federal, conduzido no âmbito da investigação realizada pelo Consórcio Bertha Lutz durante as eleições de 2010. Com base em um questionário constando perguntas relativas a diferentes dimensões individuais e institucionais em relação aos partidos, analisa-se dimensões como trajetórias politicas e eleitorais, estratégias, recursos e dificuldades de campanhas. Em seguida, por meio de determinados procedimentos metodológicos de aglomeração de variáveis, procura-se analisar perfis de eleitos e não eleitos. O objetivo é identificar como o gênero perpassa e apresenta-se em possíveis variáveis intervenientes nesses perfis. Como os resultados mostram, há varias dimensões nas quais a categoria gênero faz-se presente, de maneira direta ou indireta, em geral, antes do momento eleitoral em si. O processo eleitoral seria, assim, o resultado de um filtro que antecede mesmo o recrutamento. Conclui-se que os perfis de eleitos, homens ou mulheres, são semelhantes, mas, considerando que os homens são amplamente majoritários entre os eleitos, podese dizer que tais perfis são fruto de uma estrutura ainda marcada por desigualdades e por valores diferenciados por gênero.
\end{abstract}

PALAVRAS-CHAVE: gênero; mulheres e eleições; processo eleitoral e gênero; poder e gênero; eleições.

\section{INTRODUÇÃO 1}

$\mathrm{O}$ artigo apresenta parte dos resultados da pesquisa conduzida pelo Consórcio Bertha Lutz durante 2010 (ARAÚJO, 2010) para acompanhar e analisar o processo eleitoral como um todo. Entre outros aspectos, o Consórcio procurou "identificar de forma mais ampla os fatores que contribuem para a baixa representação de mulheres em cargos eletivos no Brasil'”. Nesse caso, o foco são as eleições para o cargo de Deputado Federal no ano de 2010, sob o ângulo das candidaturas dos candidatos $^{2}$. No contexto brasileiro da Representação Política, o acesso à Câmara Federal constitui o principal e mais emblemático déficit de participação feminina (ARAÚJO, 2001; 2009; ALVARES, 2004; ALVES \& CAVENAGHI, 2005; ARAÚJO \& ALVES, 2007). Essa problemática adquire maior relevância se considerarmos que a representação no poder Legislativo tem servido como um importante parâmetro eleitoral para aferir o grau de amadurecimento político dos países,

\footnotetext{
1 Gostaríamos de agradecer aos pareceristas anônimos da $R e$ vista de Sociologia e Política por sua contribuição para este artigo.

2 Para esse nível eleitoral, a pesquisa do Consórcio foi dividida em dois blocos: a análise dos candidatos e a análise dos partidos. Outros pesquisadores do Consórcio ficaram responsáveis por outras partes de candidaturas e pela investigação dos partidos como unidade de análise.
}

quanto à igualdade entre os sexos. Desse modo, conquanto o caso brasileiro guarde suas peculiaridades, ele também se insere em processos mais gerais que envolvem as democracias representativas contemporâneas, com seus dois atores centrais envolvidos nas competições legislativas, candidatos e partidos, além da natureza da representação em debate: descritiva e/ ou substantiva. Conquanto muitos dos tópicos discutidos abaixo também contenham elementos de debate sobre a natureza e a percepção de representação, a partir dos candidatos, o foco do artigo é o primeiro tópico. Assim, observamos itens associados ao "recrutamento político" e às "estratégias eleitorais" que envolvem trajetórias, recursos e obstáculos, com base na unidade de análise "candidatos". Para tanto, apoiamo-nos na perspectiva que foi sintetizada de modo bastante abrangente por Norris (1993) no seu "Modelo do processo do recrutamento político", até hoje uma importante referência analítica.

A vantagem do modelo de Norris é que, embora voltado para o recrutamento político e os resultados eleitorais, ele pressupõe a articulação desses processos com amplas dimensões socioeconômicas, culturais e do próprio sistema político-eleitoral. Ou seja, a compreensão da política como ação eleitoral necessariamente está relacionada com ambientes externos e históricos à volta desse momento específico. Reproduzimos aqui, de modo bastante sumário, seus pressupostos e componentes. A autora parte de duas 
dimensões relacionadas a um processo de recrutamento eleitoral: o que denomina de "demanda" (dos partidos com vistas à composição de suas listas) e o que denomina de "oferta" (aqueles indivíduos disponíveis e/ou potencialmente elegíveis). Demanda e oferta ocorrem e realizam-se em cenários mais amplos do sistema político, e envolvem a cultura política, o sistema partidário e a competição legislativa em si, ou seja, o contexto específico de cada disputa eleitoral. Além desses níveis, incluem-se, também, as configurações do "sistema partidário", no interior do qual a autora destaca como relevantes, a "ideologia" e a "cultura organizacional" de cada partido.

Do lado da oferta, tal processo está relacionado com os indivíduos (candidaturas), e é atinente ou envolve os seguintes aspectos: $(i)$ a "origem social" (nesse caso, a origem refere-se aos tipos de públicoseleitores para os quais o partido pretende dirigir-se ou dos quais o partido pretende obter apoio e votos); (ii) as "motivações" (envolvem as razões, estímulos e contextos que levam os indivíduos a desejarem ou estarem dispostos a candidatar-se); (iii) os "recursos" (compreendidos como um conjunto que transcende a dimensão financeira e envolve tudo o que pode constituir-se em "capital político"); (iv) por último, o que define como o "pool" de elegíveis, ou seja, um conjunto de competidores que reúne mais condições e mais chances de ser eleito dentro desse vasto conjunto.

Do lado da demanda estão os partidos políticos. Em seu interior destacam-se dois níveis centrais: as "regras definidoras da seleção" (ou seja, tanto as regras formais e gerais como as regras informais que presidem a cultura interna e o contexto no qual o partido está disputando) e os próprios "selecionadores" (aqueles, em geral, dirigentes e membros de órgãos decisórios dos partidos, que definem as estratégias e necessidades políticas centrais para um dado contexto eleitoral). Com base nisso e nas dimensões partidárias referidas anteriormente, define-se o conjunto de indivíduos que comporá a lista de competidores. Em outro ponto do processo, a autora identifica os votantes e os resultados eleitorais. Falamos de "um ponto do processo" porque esses próprios votantes e resultados também comporão as dimensões anteriormente citadas em relação à oferta, em um jogo cíclico, orientado pela repetição nas suas regras, mas sempre redefinido pelos contextos de cada processo.

O modelo de Norris tem sido uma importante referência na literatura tanto para pensar a problemática teórica mais geral, abordando aspectos como os partidos, a cultura política, o sistema eleitoral ou ainda as trajetórias de candidaturas, como para estudos de caso e níveis mais localizados - e por tal motivo tomamo-lo como referência para tentar observar algumas das dimensões mencionadas acima sob o ângulo da "oferta", ou seja, dos candidatos ${ }^{3}$. Tais percursos passam pelas trajetórias e perfis de carreiras que formarão os potenciais competidores (MIGUEL, 2003) e pelas estratégias de recrutamento político levadas em conta no ambiente sistêmico e político das competições (NORRIS \& LOVENDUSKI, 1996; ALVARES, 2004), os quais se relacionam com os processos eleitorais, ou seja, os recursos de campanha, as variáveis do sistema eleitoral e os contextos políticos em que estão competindo.

$\mathrm{O}$ estudo em foco foi estruturado buscando obter elementos e tentar responder a algumas perguntas consideradas como centrais. Perguntamo-nos sobre aspectos endógenos e exógenos ao sistema eleitoral, relacionados com as dimensões acima e que influenciam as decisões dos indivíduos a tornarem-se candidatos, podendo determinar suas candidaturas e, quando observados na perspectiva de gênero, operam para viabilizar ou obstaculizar o ingresso de mulheres nos cargos legislativos. Em síntese, nosso objetivo consistiu em tentar identificar as principais barreiras e estímulos que acompanham o percurso entre as potenciais candidaturas e o "pool" de elegíveis até a eleição efetiva. Outras pesquisas já se basearam no modelo discutido para realizar estudos de processos eleitorais, ou fizeram-no de diferentes maneiras (ARAÚJO, 1999; ALVARES, 2004; ARAÚJO \& ALVES, 2007; BOLOGNESI \& COSTA, 2009; SPECK \& SACCHET, 2012b). A particularidade, nesse caso, consistiu na tentativa - parcialmente realizada - de ampliar a unidade de análise, o processo eleitoral em curso, e na ampliação do escopo de questões investigadas ${ }^{4}$.

No segundo momento da análise, buscamos identificar agregações de indivíduos cujas trajetórias, perfis e/ou capitais aproximassem-se ou distanciassem-

\footnotetext{
3 É importante lembrar que o lado da "demanda", ou dos partidos, foi também analisado na pesquisa do Consórcio. Para o estudo das candidaturas tendo como informantes os candidatos, foi construído um questionário, no qual se buscou contemplar ao máximo as dimensões propostas no modelo de Norris. $\mathrm{O}$ questionário tomou por base, também, outros já aplicados nesta mesma perspectiva (ARAÚJO, 1998; MARX, BORNER \& CAMINOTTI, 2007).

4 Em relação ao primeiro aspecto, saindo de estudos localizados e roteiros mais abertos para uma amostra nacional, com representatividade para duas regiões, Sul e Sudeste, incluindo informantes de 14 estados e um questionário fechado. No segundo aspecto, o fato de trabalharmos com indivíduos já selecionados como candidatos e em pleno processo eleitoral ou imediatamente após tal processo. E incluirmos perguntas envolvendo suas percepções e informações sobre seus partidos, sobre suas trajetórias e sobre construções sociais de gênero na política.
} 
se mais de perfis vencedores ou perdedores ${ }^{5}$.

\section{PROCEDIMENTOS METODOLÓGICOS}

Com base nas dimensões discutidas e visando obter informações dos próprios candidatos, construímos uma articulação de procedimentos com as seguintes fontes: (i) uma pesquisa amostral baseada em questionário estruturado que ouviu candidatos ao cargo de Deputado Federal em 14 estados do país; (ii) dados fornecidos pelos candidatos ao Tribunal Superior Eleitoral (TSE) ou construídos pelo próprio, relacionados com a condição de eleição e as informações relativas à prestação de contas de campanha oficialmente informada ao TSE pelos candidatos.

\section{II.1. Metodologia da pesquisa amostral com candi- datos}

Aqui, por questões de espaço, é suficiente informar que a amostra selecionada cobriu 14 estados. A amostra é estratificada, representativa das regiões Sul e Sudeste e inclui estados das demais regiões. O peso dos partidos correspondeu à proporcionalidade dos mesmos na Câmara de Deputados na legislatura de 2006 a 2010. Os dados trabalhados neste artigo, assim como no Relatório Final (ARAÚJO, 2010), são resultantes de reponderação, cuja base de dados original foi anexada ao Relatório. A amostra inicialmente definida era de 200 entrevistas, mas sofreu uma perda com uma não realização ao redor de $33 \%$ delas. Ao final foram coletados 134 casos - 66 Homens e 68 Mulheres. Após estudar a viabilidade de uso dos estratos iniciais, foi feita uma reponderação das probabilidades iniciais de seleção e pesos amostrais necessários, dado que a mesma não era proporcional. Os dados trabalhados neste artigo, assim como no Relatório Final, são resultantes dessa reponderação, cuja base de dados original foi anexada ao Relatório.

Os estados contidos na amostra foram: São Paulo (27), Rio de Janeiro (22), Minas Gerais (12), Paraná (99), Bahia (9), Rio Grande do Sul (9), Pernambuco (3), Amapá (3), Goiás (2), Santa Catarina (2), Distrito

\footnotetext{
5 No artigo escrito para a Coletânea (ARAÚJO \& BORGES, 2012a), com base nos resultados gerais, desenvolvemos uma segunda parte. Nessa, buscamos entender como certas características encontradas aproximam-se, distanciam-se ou interagem com outras características identificadas via análise da literaturaem particular, a magnitude dos partidos aos quais os candidatos pertencem e/ou de dados fornecidos por esses mesmos candidatos ao TSE - nesse caso, os gastos declarados de campanha. Isso foi feito, posteriormente, em articulação com dados empíricos coletados do TSE. Um elemento adicional considerado na análise foi a nova Lei de Cotas e o que mudou em sua implantação e em seus possíveis impactos. Essa segunda parte tem como fontes centrais dados oriundos do TSE.
}

Federal (1), Amazonas (1) e Sergipe (1). O universo corresponde a 3125 candidatos oficialmente registrados no TSE em agosto de 2010: 2522 homens e 603 Mulheres. Adicionalmente, devido ao número muito pequeno de candidatos em alguns partidos, estes foram reagrupados da seguinte maneira: DEM; PMDB; PR e PP; PSB, PTB e PDT; PSDB; PT e "Pequenos" (todos os demais partidos). A pesquisa foi realizada entre os meses de novembro de 2010 e fevereiro de 2011, por meio de questionário estruturado via CATI (Computer Assisted Telephone Interview) ${ }^{6}$. Assim, se por um lado a coleta parcial entre os estados e a redução do tamanho original da amostra exige parcimônia e não nos permite fazer generalizações, por outro lado, o fato de podermos contemplar uma base que compreende boa parte dos estados da federação permite-nos falar aqui de características e padrões que se aproximam de modo razoável de uma amostra nacional.

As questões do survey previam respostas únicas ou respostas múltiplas que poderiam ser respondidas, também, por ordem de prioridades-importância. Por meio do seu conteúdo, foram exploradas trajetórias e mediações no recrutamento, bem como questões partidárias e individuais dos candidatos. As questões envolveram o próprio processo eleitoral, considerando trajetórias pessoais e políticas, aspectos do recrutamento eleitoral, recursos - financeiros e não financeiros - e redes de campanha. Ou seja, aspectos que, juntos, ajudam a definir a viabilidade de uma candidatura. Abordou-se, ainda, o que os candidatos propõem e como propõem suas agendas de ações (suas promessas). Pelo motivo de as dimensões sistêmicas da política constituírem uma das partes desses processos, foram explorados também aspectos relacionados com dimensões da vida dita "privada" ou "não pública", em particular alguns atinentes à família e às carreiras profissionais. Mais uma vez, o olhar volta-se para compreender como as mulheres inserem-se nesses caminhos ${ }^{7}$.

Organizamos o trabalho da seguinte forma. A primeira parte expõe e discute a pesquisa amostral com candidatos. Faz-se uma análise sintética dos dados do survey considerados centrais na perspectiva multidimensional tratada ${ }^{8}$. Apresentam-se, de modo descriti-

6 Questionário aplicado aos candidatos encontra-se no Anexo do Relatório Final do Projeto Consórcio Bertha Lutz.

7 Agradecemos à colega Suzana Cavagnaghi pelo trabalho de cálculo amostral e de reponderação da amostra, cujo detalhamento de procedimento encontra-se no Relatório mencionado (ARAÚJO, 2010).

8 Em virtude do espaço, são apresentadas apenas as considerações principais sobre os dados encontrados na pesquisa com candidatos. A apresentação dos mesmos em termos estatísticos, 
vo, os traços gerais encontrados nas respostas de candidatos e candidatas em cada uma das dimensões; em seguida, apresentam-se resultados de uma análise de cluster construída com as mesmas variáveis e algumas obtidas diretamente do TSE, cujo intuito foi identificar traços comuns ou que estão mais presentes nos candidatos, inclusive o sexo. Com isso, mapeamos traços que compõem um cluster de eleitos. O sentido de articular os dois movimentos foi o de mapear características mais presentes e constantes nesses três blocos de indivíduos. Busca-se, com isso, pensar sobre os obstáculos e incentivos encontrados nos caminhos que os indivíduos percorrem ao tentarem ou efetivamente tornarem-se parte da "elite política". A questão mais geral que orientou essa parte da análise foi a de saber em que medida fatores indicados pelos candidatos, em suas respostas ao survey ${ }^{9}$, surgem como padrões para predizer a elegibilidade.

\section{AS BARREIRAS, AS BRECHAS E A RECONS- TITUIÇÃO DOS LUGARES DE GÊNERO-UMA ANÁLISE DOS CANDIDATOS E DE SUAS INFORMAÇÕES COM BASE NO SURVEY}

\section{III.1. Informações metodológicas}

As informações metodológicas básicas sobre a amostra de entrevistados encontram-se no anexo deste artigo. O informe detalhado da construção da amostra é apresentado no Relatório de Pesquisa do Consórcio Bertha Lutz (ARAÚJO, 2010). Na análise abaixo, para efeito didático, selecionamos e agregamos, em grupos, perguntas do questionário que consideramos aproximarem-se dos objetivos delineados anteriormente. As perguntas selecionadas encontram-se no Anexo 2. Os subtítulos definem os conteúdos das questões. Em algumas delas cabiam múltiplas respostas e, em outras, apenas uma escolha. Embora com um universo limitado e, em muitos casos, números estatisticamente pouco robustos, destacamos aqui o sentido indicativo das respostas, reforçado por achados anteriores em diferentes investigações, bem como a sua efetividade como novo ponto de partida para futuras investigações.

\section{III.2. Os entrevistados: perfil sócio-demográfico e vínculos sociais}

A população estudada distribuiu-se em 19\% de mulheres e $81 \%$ de homens. Assim como no universo de candidatos, a escolaridade é bastante elevada. Mais

bem como sua análise, está disponível no Relatório do Consórcio. Aqui faremos breves referências a dados estatísticos e apontaremos, sobretudo, o que tais dados sugerem.

9 Impossíveis de identificação em dados mais gerais do TSE, como foi feito na análise para edição dos resultados gerais do Consórcio. de $50 \%$ possui curso superior. Mulheres apresentam escolaridade mais elevada, sobretudo entre eleitos. A distribuição percentual entre casados e solteiros é equilibrada em ambos os sexos, mas entre as mulheres há mais solteiras do que casadas. A faixa etária que mais concentra pessoas é a de 18 aos 39 anos. Há mais mulheres nessa faixa, ao passo que há mais do que o dobro de homens na faixa acima de 60 anos. A maior parte tem filhos, mas a média de filhos é mais elevada entre os homens $(2,46)$ do que entre as mulheres $(1,59)$. Os católicos concentram os percentuais mais elevados em ambos os sexos (41,5\% entre as mulheres e 58,3\% entre os homens). Há uma diferença considerável entre homens e mulheres na segunda religião mais escolhida $(31 \%$ das mulheres disseram-se pentecostais contra $8,1 \%$ dos homens), dado que corrobora outras pesquisas que ressaltam o papel dessa religião para as mulheres. No quesito cor ou raça, a maioria identificou-se como branca, seguida de parda e preta (respectivamente, 49,2\%, 36,1\% e $13,4 \%$, entre as mulheres, e $37,8 \%, 37,0 \%$ e 7,3\%, entre os homens). Em se tratando de ocupação atual, a maior parte das candidatas estava ocupada no setor público. Em seguida encontra-se o trabalho por conta própria, emblemático da concentração de mulheres nesse setor, em geral, informal. Os candidatos exercem mais profissões vinculadas ao setor privado. Agregando-se as ocupações atuais visando identificar quem tem e quem não tem cargo político, constatamos que a maioria não ocupava cargos na época da entrevista. Entre os que ocupavam, a proporção de homens é ligeiramente mais elevada do que de mulheres (respectivamente 19,0\% e 16\%). No que diz respeito ao perfil partidário, segundo agregação por tamanho (pequeno, médio e grande) ${ }^{10}$, a maior parte pertence aos partidos pequenos, seguida dos partidos grandes e depois dos médios (respectivamente, 49,3\%, 29,5\% e $21,2 \%$ na população feminina e $48,2 \%, 32,3 \%$ e $19,5 \%$ na população masculina).

\section{3. Motivações que constroem caminhos da inserção partidária e eleitoral}

Por que determinadas pessoas motivam-se a disputar um processo eleitoral e outras não? E por que, proporcionalmente, menos mulheres dispõem-se a fazêlo? Há um debate considerável sobre isso, sobretudo em relação ao peso dos obstáculos estruturais e institucionais sobre os indivíduos vis-à-vis sua

\footnotetext{
10 Grandes: Democratas (DEM), Partido do Movimento Democrático Brasileiro (PMDB), Partido dos Trabalhadores (PT) e Partido da Social Democracia Brasileira (PSDB). Médios: Partido da República (PR), Partido Socialista Brasileiro (PSB), Partido Progressista (PP), Partido Trabalhista Brasileiro (PTB) e Partido Democrático Trabalhista (PDT). Pequenos: os demais.
} 
autonomia de escolha. Phillips (1995; 1998), por exemplo, é uma das autoras que frisa o peso de fatores externos para explicar a diferença na participação de homens e mulheres e, inclusive, defender as cotas. Contudo, ao mesmo tempo, nega-se a tomá-las (as cotas ou outras demandas numéricas, como por exemplo, a paridade), como autoevidentes e/ou sustentadas, sobretudo, no princípio da presença e da inclusão equitativa nos espaços políticos. Concordamos com as duas observações da autora ao fazermos perguntas relacionadas às trajetórias e estímulos. Ou seja, embora nem todos queiram exercer cargos e ser representantes políticos, há o fato, evidenciado histórica e numericamente, de que o "gap" da desigualdade na representação vai além de uma decisão livre e autônoma de homens e mulheres que definiria um traço inato de gênero na tendência à participação. Tomamos como pressupostos o percurso histórico já bastante registrado e discutido na literatura. Mas não descartamos e perseguimos o interesse de identificar, dentro de um leque de possibilidades apresentadas, quais as motivações e razões centrais que marcam esse grupo em particular e como isso se insere na interação com as demandas partidárias. As questões selecionadas buscaram identificar aspectos determinados, das trajetórias pessoais e públicas, que levaram esse grupo a interessar-se pela política. Com isso, pretende-se, também, pensar traços recorrentes para grupos mais amplos.

Assim, no levantamento feito, as principais motivações para o ingresso na carreira política, para ambos os sexos, foram "ideológicas" (mulheres 55,4\% e homens 71,8\%), seguidas de "experiência de militância e participação anterior em outras organizações" (na ordem anterior, $28,9 \%$ e $27,6 \%$ ). Observou-se que as alternativas explícitas de "motivações coletivas" tiveram baixos índices de respostas positivas ${ }^{11}$. Os estímulos advindos de familiares políticos são baixos para ambos, mas homens explicitam mais $(8,5 \%)$ do que as mulheres $(4,5 \%)$ esse tipo de estímulo.

Segundo Chapman (1993), o quer que seja considerado como recurso que agregue para a política, os homens tendem a deter mais desse recurso do que as mulheres. Em nosso survey entre candidatos essa constatação não foi diferente. Na pergunta com múltiplas respostas (correspondente à questão 58 do questionário), entre os diversos tipos de estímulos citados para tornar-se candidato, na maioria envolvendo algum tipo de recurso como capital políti-

\footnotetext{
11 Embora motivações ideológicas e experiência de participação anterior contenham também tal dimensão.
}

co, os homens responderam à frente das mulheres em termos percentuais. Foram duas as exceções: ser político naquele momento, ou seja, ocupar algum cargo obteve $16,8 \%$ entre mulheres e $11,2 \%$ entre homens. E ser militante há muito tempo e conhecer bem o partido. Na motivação política pessoal para tornar-se candidato, as opções mais escolhidas foram "militância no partido" e "vontade própria de transformar a ação política em atuação no Legislativo ou no Executivo". "Proposta de organização social" e de "movimentos nos quais participava" vieram em seguida. Em terceiro lugar, foi mencionado o convite de pessoas do partido e, em quarto, o fato de já ser ou ter sido parlamentar. Quando se observa por sexo, nota-se que, em ambos, há a predominância de uma motivação orientada pela "militância" e a vontade de transformá-la em atuação parlamentar. Entre os homens, o motivo "participação em uma organização" vem logo em seguida. Convite de pessoas do partido apresentou-se com peso. Só posteriormente surge a participação em uma organização coletiva. O convite em função da Lei de Cotas também foi razoavelmente mencionado, o que sugere que a segunda alternativa também pode ser derivada do estímulo-necessidade das cotas. Ainda que "residual" no número de respostas, as mulheres citam mais do que homens a influência político-familiar para candidaturas.

Tanto para homens como para mulheres, as trajetórias públicas individuais e a liderança pessoal constituíram as principais motivações. As "motivações pessoais" mesclam-se com as "trajetórias políticas". Ter "liderança no local ou região onde moram" foi bem mencionada pelas mulheres ( $38,9 \%)$, e obteve menção ainda mais elevada entre os homens (41,9\%).

Isso sugere que o peso de uma base regional para estímulo à competição pode ser relevante não só para os níveis mais locais de disputa. O "tempo de vivência partidária" é importante. Entre as razões para candidatar-se, destacaram-se, também, a ocupação de cargos públicos ou partidários e o fato de ser figura pública conhecida. Motivos associados à atuação coletiva ou vínculos associativos só vieram posteriormente. Os homens respondem por 33\% dos que atribuem a candidatura a projetos pessoais, e as mulheres respondem por $56 \%$, ou seja, mais da metade. Mais uma vez, a existência de outras experiências familiares na política demonstrou ter peso bem menor, mas, ainda assim, é o dobro para os homens, em comparação com as mulheres. Razões éticas e altruístas são pouco mencionadas por ambos os sexos. O histórico de inserção política anterior surge como um elemento importante para estimular a inserção partidária, e mesmo as candidaturas. As trajetórias públicas que conferem liderança pessoal destacaram- 
se entre as motivações. Contudo, o peso do histórico familiar parece estar reduzindo-se, sugerindo maior institucionalização e diversificação de caminhos ${ }^{12}$.

\section{III.4.Outras formas de recursos: trajetórias e expe- riências públicas}

Seguindo o fio condutor anterior, procuramos verificar os traços centrais das trajetórias individuais associados com a ocupação de "cargos públicos e que se transformam em potenciais capitais eleitorais". Consideramos, também, que familiares que exerceram ou exercem cargos operam como canais de acesso e estímulo ao ingresso na política. A maior parte dos entrevistados não havia ocupado cargos. Entre os que ocuparam, um pouco mais de homens (36\%) do que de mulheres tinham-no feito (30\%). A ocupação de "cargos por familiares", já tratada, é reveladora do traço de gênero na política: seis em cada dez homens respondeu afirmativamente à pergunta; ao passo que, entre as mulheres, cerca de quatro em cada dez. A maior parte diz já ter alguma experiência de participação pública em cargos, sejam eles associativos, sejam privados, mas também aqui esta é mais comum entre os homens do que entre as mulheres. Contudo é ainda mais revelador que, no quesito ocupação de cargos no poder Legislativo ou no poder Executivo, bem mais homens $(48,4 \%)$ do que mulheres $(30,1 \%)$ tiveram tal experiência. De igual modo, à pergunta sobre se ocupou ou participou de direções e/ou cargos em alguma organização (acadêmicos, em ONGs, organizações sindicais, profisssionais ou movimentos sociais), 43,1\% mulheres não o tinham feito e, entre os homens, $34,9 \%$. Como se observa, as trajetórias de homens e mulheres em relação à ocupação de cargos públicos revelam um padrão interessante: os homens possuem mais experiência em todos os tipos de cargos mencionados ${ }^{13}$.

\section{III.5. Outros recursos: inserção e experiência partidária}

Nos estudos sobre eleições, sistema eleitoral, partidário, relação poder Executivo-poder Legislativo e recrutamento político, a outra "ponta" ou unidade relevante de análise são os partidos políticos. Como a

\footnotetext{
12 Em um exercício exploratório dos dados, no qual nos perguntamos onde estão as mulheres vencedoras, descobrimos que estas aproximam-se mais dos perfis encontrados para os homens, sobretudo em se tratando da ocupação dos cargos. A trajetória parlamentar confirmou-se entre os eleitos. Ser ou já ter sido parlamentar praticamente mantém-se estável e quase empata com as motivações de experiência de militância.

13 A pergunta 19 foi agregada dado o pequeno número de resposta em cada subitem. Assim, em alguns casos, como associações de moradores, as mulheres tinham experiência maior, porém, no agregado, essa experiência é maior entre os homens.
}

vida e as organizações partidárias relacionam-se com as motivações, as possibilidades de candidaturas e as possibilidades de formação de capitais eleitorais? Saber (i) como se constroem essas trajetórias internas; (ii) em que medida os candidatos têm uma inserção que lhes garante apoio e (iii) qual o peso dessa relação na eleição, foram aspectos que procuramos explorar.

Ao contrário de certa crença, neste caso, os candidatos em geral têm um tempo razoável de filiação. A maior parte (65\% dos homens e $56 \%$ das mulheres) tem mais de oito anos de vida partidária. Na média, os homens têm mais tempo de militância partidária do que as mulheres ( 8,16 anos e 7,48 , respectivamente); e entre aqueles com mais de dez anos, os homens são também maioria. O percentual de mulheres é ligeiramente maior do que o de homens entre aqueles com até dois anos de filiação, o que sugere que as mulheres estão começando a ingressar de modo mais sistemático nessas organizações.

A maioria não ocupa cargos partidários, mas, entre os que ocupam, as mulheres são um pouco menos (33\%) do que os homens (38\%). Ser dirigente partidário pode ser um importante estímulo e base para a disputa eleitoral. E os cargos considerados mais relevantes por homens ou por mulheres podem ser emblemáticos dos espaços ocupados pelos mesmos. Homens destacaram, sobretudo, os cargos de Presidente e Coordenador Executivo. Mulheres destacaram principalmente a condição de fundadoras e, entre os cargos, os de Secretário, Tesoureiro e Conselheiro. Quatro em cada cinco eleitos ocupavam cargos no partido, o que reforça a relação constatada. Experiência eleitoral, familiaridade com campanhas e, consequentemente, com a dinâmica partidária, são aspectos mais presentes entre os homens (64\%) em comparação com as mulheres (43\%).

A percepção de "resistência à candidatura" pode ser considerada elevada entre respondentes, correspondendo a cerca de $1 / 3$ do total. Sobre tal percepção, $38,5 \%$ de candidatas e $30 \%$ dos candidatos responderam afirmativamente. Como objetos da resistência, o próprio partido foi o mais mencionado, por ambos os sexos. Homens mencionaram bem mais esse fator. Isso nos permite especular sobre o caráter intrapartidário da competição e as expectativas internas associadas, por um lado, ao apoio solicitado ou esperado e, por outro, ao apoio efetivamente recebido. Outra hipótese a ser explorada posteriormente é a de que os atores do jogo político da competição já estariam definidos, de modo que tanto a demanda de candidatas ao partido como as respostas destes às mulheres tenderiam a ter um caráter menos conflituoso. Em outras palavras, as mulheres não mencionam, tanto quanto os homens, terem sofrido resistência partidária. 
Parece-nos apropriado pensar também em outra leitura: ou seja, a da vulnerabilidade ou exterioridade ao jogo da competição do que propriamente apoio às mesmas.

$\mathrm{O}$ "processo de formação das chapas para dirigentes internos/ partidários" é conhecido por mais da metade dos entrevistados (54\%). Mais mulheres (57\%) mostram-se informadas do que os homens (53\%). Embora poucos, numericamente - entre os eleitos, quatro em cada cinco informaram conhecer esse processo - para a maioria dos homens (44\%), as "decisões para o processo de formação das chapas para dirigentes internos são decisões mais informais". Nas percepções da maior parte das mulheres, essas são "decisões formais, realizadas através de assembleias e votações prévias": $53,7 \%$ de mulheres consideraram o processo formal, contra $35 \%$ dos homens.

Outro tópico tratado foi o conhecimento sobre o "processo de formação de chapas eleitorais no partido". A maior parte (seis em cada dez entrevistados) disse conhecê-lo. O índice de respostas por sexo é idêntico. Contudo, entre os eleitos essa percepção de conhecimento é bem maior: oito em dez eleitos responderam conhecer o processo. Dizer que conhece remete à percepção que o indivíduo tem da questão. Contudo, a percepção de que conhece o processo não necessariamente implica domínio de sua dinâmica efetiva em seus desdobramentos práticos. Os homens escolheram respostas mais pragmáticas: $62 \%$ deles concordaram que a lista é composta a partir do peso eleitoral dos candidatos. Essa foi a segunda escolha das mulheres (52\%). Entre estas, o critério mais mencionado (59\%) foi também político, porém mais plural: "compor uma lista representativa de estado e município, assim como compor lista considerando os diversos grupos políticos". A crença do que podemos definir como um "pluralismo nos critérios de escolha de candidaturas pelo partido" parece ser mais forte entre mulheres. Aqui, assim como nas escolhas sobre o processo de construção de chapas, não é de todo infundado sugerir que há uma percepção mais pragmática entre os homens e mais formal entre as mulheres. O que, provavelmente, ocorre pelo fator maior inserção, tempo de vida partidária e tempo de militância, entre outros aspectos.

Embora a literatura aponte ${ }^{14}$ para a ausência de apoio partidário às mulheres nas campanhas, é interessante notar que a percepção desse grupo de entrevistados - homens e mulheres - sobre essa relação, durante

\footnotetext{
14 Muitas vezes, com base em pesquisas com parlamentares ou dirigentes partidários. E, nesta pesquisa, o artigo sobre os gastos de campanha (ARAÚJO \& BORGES, 2012a) aponta para um possível gap na ajuda financeira efetivamente dada às mulheres e aos homens.
}

o período eleitoral, é inversa ao esperado. Homens tenderam a avaliar o apoio prestado de maneira bem mais negativa do que as mulheres; ou tenderam a demonstrar autonomia do partido em suas estratégias de campanha. Seis em cada dez mulheres consideraram que predominou "boa convivência e apoio necessários", oriundo do partido durante e para a campanha. Pouco mais de um terço dos homens escolheram esta opção. Por outro lado, praticamente o dobro de homens, em comparação com as mulheres, responderam ter uma atuação/campanha independente do partido. Ou seja, indicam que recorrem ou recorreram a outros tipos de apoios e redes.

O partido surge como importante veículo e referência de campanha, mas mulheres "demonstram menor descontentamento na relação com estas organizações" e homens apontam para uma "maior independência e outras possíveis redes de apoio". Como ler esses dados diante do que temos encontrado na literatura? Parece-nos pouco provável que, efetivamente, as mulheres, em geral, tenham recebido uma atenção e uma disponibilidade de apoio maior do que os homens. Assim, primeiro, há a necessidade de uma verificação empírica mais efetiva sobre o que e como recursos, participações e escolhas foram feitos e mediados entre partidos e candidatos. Sobre isso, cabe assinalar que, em estudo exploratório anterior (ARAÚJO, 1999), no qual se pedia para os candidatos (de ambos os sexos) indicarem o que obtiveram dos partidos, já se encontraram diferenças muito pequenas, por sexo, entre os tipos de recursos distribuídos. Com efeito, essas diferenças eram maiores entre candidatos com chances eleitorais e candidatos sem chances eleitorais do que entre os sexos. Por último, dois aspectos parecem-nos importantes para reter. $\mathrm{O}$ primeiro está relacionado aos critérios formais e efetivos do recrutamento partidário. Nesse caso, o recrutamento teria de ser pensado como aquele que ocorre para formar uma chapa e responder a eventuais necessidades e, ao mesmo tempo, como aquele efetivamente destinado a obter ganhos de representação no momento eleitoral. O segundo aspecto diz respeito à riqueza e à diversidade de dinâmicas presentes no processo de competição em si. Isso, por sua vez, remete-nos ao peso e ao papel do partido no processo específico.

Mais de oito em cada dez entrevistados não têm conhecimento dos critérios usados pelos seus respectivos partidos para a distribuição de recursos entre os seus candidatos. Isso nos sugere um processo centralizado em torno da direção partidária. Entre os que disseram conhecer, a maior parte acredita que os recursos vão mesmo para os candidatos que têm mais chances de eleger-se. E, nesse caso, homens e mulheres compartilham da mesma percepção. 
A avaliação quanto aos recursos obtidos via partido, pelos próprios candidatos é extremamente negativa, para ambos os sexos. E mais negativa para os homens: $80 \%$ deles avaliam que tais recursos ficaram abaixo do esperado e só $15 \%$ avaliou ter sido dentro do esperado. Entre as mulheres, esses números melhoram um pouco: $61 \%$ avaliam abaixo do esperado e $28 \%$ dentro do esperado. Por outro lado, é muito sintomático que quando olhamos o microuniverso dos que foram eleitos e estavam na amostra, sete em cada dez homens e cinco em cada dez mulheres disseram/atribuíram a sua vitória ao apoio partidário, o que reforça a hipótese aventada anteriormente.

O baixo índice de conhecimento na distribuição dos recursos partidários mostrou-se também em relação aos critérios para a distribuição do tempo do Horário Gratuito de Propaganda Eleitoral (HGPE). Menos de $1 / 3$ dos entrevistados têm conhecimento dos critérios do partido para distribuição do tempo. Mais uma vez a percepção sobre o conhecimento do processo é maior entre as mulheres ( $40 \%$ contra $25 \%$ dos homens). Observamos mais uma vez que, entre os eleitos, há uma inversão: a maior parte informou ter conhecimento dos critérios da distribuição de tempo. Contudo, mais de $50 \%$ delas responderam que não apareceram uma vez sequer no HGPE, contra $14 \%$ dos homens. Como percepção, a dedicação integral à campanha obteve bem mais respostas entre as mulheres $(77,4 \%)$ do que entre os homens $(50,8 \%)$. A possibilidade de "homens laranja", geralmente aventada para as mulheres é um aspecto a considerar. Como instrumentos preferenciais de contatos, verificou-se que o tradicional "corpo a corpo" é bem mais citado pelas candidatas $(75,6 \%)$ do que por candidatos do sexo masculino $(50,8 \%)$. De outra parte são os homens que mais registram recursos impessoais, envolvendo recursos midiáticos, carros de som, panfletos, entre outros. Três questões podem ser consideradas e exploradas em futuros trabalhos: (i) o significado subjetivo desses tipos de recursos pelos candidatos. Assim, talvez o corpo a corpo soe como um traço mais pessoal e, portanto, mais facilmente assimilável e assimilado por candidatas na sua condição de mulher; (ii) os efetivos recursos a que todos têm acesso. Nesse caso, o corpo a corpo não seria uma escolha, mas a estratégia possível a ser privilegiada; (iii) por último, a relação entre tais estratégias e a sua eficácia, bem como a referência que o próprio eleitor tem na sua formação de posição sobre em quem votar. Quanto a isso, o resultado do survey conduzido pelo Consórcio, junto à população, dá-nos um bom indicativo ${ }^{15}$.

\footnotetext{
15 Pesquisa de Opinião com a população brasileira em idade de votar, realizada no âmbito da pesquisa do Consórcio Bertha Lutz no ano de 2010 e publicada com os dados do Anexo 3.
}

\section{III.6. Estratégias eleitorais e consistência de} campanha ${ }^{16}$

A literatura já vem há algum tempo trabalhando com um conceito mais amplo de "recursos". Sem descuidar do aspecto financeiro, tem-se mostrado que, a depender das regras do sistema eleitoral, do perfil do candidato e da sua área de influência-liderança, candidatos podem obter bons resultados ainda que não disponham de muitos recursos financeiros, sejam individuais, sejam partidários. Quais os recursos, individuais e coletivos, que os candidatos portam antes, ou que são acionados no momento das campanhas? E qual a avaliação que fazem dos mesmos? O intuito das perguntas e dessa agregação foi identificar o que se obtém no momento da campanha e o que pode ou não oferecer maiores chances eleitorais. Com isso, pretendemos explorar e refletir se as campanhas tinham consistência; quem estava, de fato, no grupo dos competidores efetivos e em que circunstâncias as candidaturas teriam um caráter mais formal, isto é, não seriam "para valer". Além das trajetórias, a preparação e a construção de estratégias podem ser pensadas nesse sentido.

Menos da metade dos entrevistados fez algum curso de liderança política ${ }^{17}$. Um pouco mais de mulheres do que de homens (50\% e 52\%, respectivamente), já tinha algum curso preparatório. A maioria não realizou esse tipo de curso antes da primeira disputa eleitoral. Entre os eleitos, uma parte muito pequena respondeu ter feito algum curso dessa natureza. E por que isso importa? Um aspecto muito mencionado quando se discute o investimento e apoio dos partidos às candidaturas tem sido o de preparar as candidatas por meio de cursos, informações etc. Será que tal ação pesa, de fato? Resolveria ou constituir-se-ia em um tipo de investimento eficaz para estimular as candidaturas ou, sobretudo, para a competitividade das mesmas? Eis outra questão a investigar de modo mais detalhado.

\footnotetext{
16 Ao tentarmos captar indícios do que poderia constituir-se em uma campanha mais consistente, menos consistente ou mesmo apenas formal, e como isso é mediado pelo gênero, não desconhecemos dois aspectos: $(i)$ os próprios indicadores de consistência, ainda que baseados em aspectos discutidos na literatura, foram criados pelos pesquisadores e são limitados por dimensões que fogem aos instrumentos de controle em uma pesquisa como esta; (ii) essa consistência também varia de acordo com os contextos nos quais ocorre a campanha e os perfis do candidato. Citemos, por exemplo, o indicador "aparecer no HGPE" - quase um consenso de importância na literatura. Contudo, se um candidato tiver como base eleitoral um município ou uma região mais concentrada, essa variável pode ter pequena ou nenhuma importância.

17 A pergunta não especificava se era um curso dirigido à política partidária, mas um curso de formação de liderança política.
} 
Apenas um terço dos entrevistados respondeu afirmativamente à pergunta sobre percepção de ter sentido resistência à campanha em geral ${ }^{18}$. Mas essa percepção, quando observada com mais detalhes, tende a ser bem reveladora: mulheres, mais do que homens (39\% a 30\%), informaram tal sentimento. Entre aqueles que responderam afirmativamente, a origem mais mencionada da resistência esteve localizada nos próprios membros do partido. Entre as mulheres, a menção da resistência dos familiares e, em seguida, dos amigos, é expressiva no âmbito desse pequeno universo e, juntas, ultrapassam a menção à resistência partidária. Destaca-se que a proporção dos que afirmaram sentir resistência partidária, em geral, é menor entre os eleitos. Ou seja, mais uma vez, esse olhar mais amplo para o contexto faz-se necessário e retira-nos de um discurso que pode ter apelo retórico, político, mas não necessariamente responde pelas razões do gap de gênero nas eleições.

Quase metade dos candidatos considerou o apoio geral obtido como abaixo do esperado. Em geral, há uma percepção mais positiva (apoio esperado ou acima do esperado) das mulheres (55\%) do que dos homens $(50 \%)$. Os apoios institucionais parecem ser mais freqüentes do que os apoios pessoais. Em relação aos primeiros, a Igreja foi o tipo de apoio mais mencionado por todos, seguido, na mesma intensidade, por Associação de Bairros, ONGs e sindicatos. Entre os homens, o apoio de sindicatos foi mais mencionado do que entre as mulheres. Entre estas, depois da Igreja, as Associações de Bairro foram as organizações mais mencionadas. Um em cada cinco entrevistados respondeu não ter recebido nenhum desses tipos de apoio, e isso se repete entre homens e mulheres. No pequeno universo dos que se elegeram, pela ordem, as associações de bairros, a Igreja e o sindicato, este último empatado com as ONGs e as fundações, foram os apoios mais mencionados. Ou seja: instituições e associativismo tendem a constituir-se em bases importantes para a viabilidade eleitoral. Saindo do plano institucional, encontramos que familiares e parentes são os mais citados por ambos - mas bem mais pelas mulheres. Para ambos os sexos, esse apoio viabilizouse, sobretudo, por meio de participação em comitês e no corpo a corpo. Mais mulheres do que homens citaram esta última forma e ambos citaram, em segundo lugar, a construção de redes virtuais. Contudo, mais mulheres do que homens mencionaram tais redes. Esse é outro aspecto a investigar, uma vez que a parte da pesquisa do Consórcio que cobriu os blogs constatou que, de fato, os homens utilizavam mais esse recurso ${ }^{19}$.

\footnotetext{
18 Lembremos que a pergunta em tópico anterior referia-se à resistência no interior do partido.
}

A referência à ajuda financeira ocupou o terceiro lugar, também ligeiramente mais elevada entre mulheres. $\mathrm{O}$ volume e o tipo de recursos dessa ajuda financeira, contudo, são os aspectos reveladores. Como veremos adiante, há um gap por sexo e um diferencial na origem dos recursos nesse tipo de arrecadação. Homens arrecadam mais, de pessoa jurídica e em volumes maiores. Ao passo que mulheres arrecadam mais de pessoas físicas e em volumes menores. E são claramente favoráveis aos homens.

O "corpo a corpo" foi o meio mais mencionado, por ambos os sexos, para a transmissão das mensagens e propostas, porém, foi um recurso considerado bem mais importante pelas mulheres do que pelos homens (respectivamente, $75,6 \%$ e 50,5\%). Estes, mais do que as mulheres, mencionaram instrumentos menos pessoais, tais como carro de som, mídia e o HGPE. Quando somamos duas respostas - acesso à mídia e ao HGPE - as diferenças de tipos de propaganda ficam claras. Entre os homens, 42,4\% consideraram esses meios como recursos importantes para passar suas mensagens. Já $18,6 \%$ de mulheres destacaram os dois instrumentos. Na linha de comparação que temos seguido, notamos que, entre os eleitos, os tipos de instrumentos mais citados surgem mais próximos dos perfis masculinos acima.

As informações mediadas pela percepção dos entrevistados tenderam a ser bem semelhantes às captadas via gravações do $\mathrm{HGPE}^{20}$. Em ambas, o gap de gênero é expressivo. No total, $20 \%$ responderam não ter aparecido no Horário Eleitoral. Entre os homens foram $14 \%$ e, entre as mulheres, de $53 \%$. De igual modo, nos dados coletados pelo Consórcio no HGPE, na distribuição por faixas de tempo, os homens apareceram mais nas faixas mais altas do que as mulheres. Na faixa de dez vezes ou mais, os homens eram $26 \%$ e, as mulheres, $18 \%$.

Já mencionamos, mas vale lembrar, que quatro em cada cinco entrevistados dedicaram-se integralmente à campanha. Mais mulheres ( $83 \%$ ) do que homens (77\%) informaram ter dedicação integral. Uma leitura possível relaciona-se com o perfil de quem respondeu e o impacto familiar sobre a dedicação de tempo: entre aqueles que informaram ter filhos, observou-se uma redução no percentual de dedicação integral (74\%).

Entre aqueles que não se elegeram, encontramos uma disposição expressiva de voltar a candidatar-se: 90\% dos homens responderam que pretendem

\footnotetext{
19 Ver o artigo de Machado e Steffenon (2011).

20 O acompanhamento e contagem das aparições do HGPE no âmbito dos 14 estados que estão sendo aqui analisados.
} 
candidatar-se futuramente. Entre as mulheres, 77\% disseram o mesmo. As respostas de acordo com o sexo dos entrevistados são mais uma vez emblemáticas desse diferencial de disposições e posições no "campo eleitoral" 21 . Ou seja, há $13 \%$ a mais de homens dispostos a seguir com experiências eleitorais.

A falta de dinheiro foi o fator mais mencionado, por ambos os sexos, para não tentar futuras eleições. Em seguida está a falta de apoio do partido. E, em terceiro lugar, a falta de oportunidade de exposição na mídia. A citação à falta de apoio partidário foi maior entre as mulheres. As questões financeiras e partidárias foram ainda mais percebidas entre os candidatos de partidos menores 22 .

Já entre os eleitos, buscamos captar suas percepções sobre os fatores decisivos para que o resultado final fosse bem sucedido. Entre os que se elegeram, o apoio do partido foi o principal fator apontado. Essa menção é bem mais expressiva entre os homens (sete em cada dez) do que entre as mulheres (cinco em cada dez). Campanha considerada de sucesso e ampla exposição de mídia vieram em seguida. Em respostas anteriores, manifestações de descontentamento e de independência em relação aos partidos foram expressivas, sobretudo por parte dos homens. Mas nesse caso, as mulheres mencionaram o apoio do partido como o primeiro fator, assim como os eleitos.

Candidatar-se para tornar-se conhecido, ainda que a probabilidade de eleição seja pequena, é a estratégia usual no campo político. É uma via para formar capital e tornar-se conhecido. No entanto, como vimos, o percentual de homens não eleitos que disseram pretender candidatar-se foi bem mais elevado do que o de mulheres. Aqui, futuramente, podemos explorar razões subjetivas que sustentam tais respostas. Será que mulheres entrariam acreditando mais do que os homens na efetividade e capacidade de suas campanhas? E, nesse sentido, não seriam assim tão laranjas quanto tendemos a pensar? As expectativas associadas às decepções de campanhas difíceis e baixos índices de votos fariam-nas decepcionar-se mais? E por que respondem com menos críticas aos partidos? Haveria de fato, nas respostas dos candidatos do sexo masculino, maior pragmatismo e consciência de suas (parcas) possibilidades? Assim, já entrariam nas campanhas entendendo-as como primeiro passo para

\footnotetext{
21 Tomando aqui emprestados os termos de Pierre Bourdieu.

22 As razões para a derrota eleitoral envolvem a percepção do próprio informante, e esta pode ser mediada por aspectos subjetivos, impossíveis de serem captados nesse tipo de investigação. De todo modo, são as respostas oferecidas e as escolhas mais assinaladas que queremos apresentar.
}

tornarem-se conhecidos? Qual o efeito de candidaturas anteriores com baixo desempenho sobre novas tentativas, ou seja, sobre a maioria das candidaturas, já que há um nicho que consegue um bom número de votos? Qual a relação entre esses pontos e a permanência dos baixos índices de mulheres candidatas, de um lado, e o discurso dos partidos de que "não se consegue mulheres para concorrer" $23 \mathrm{de}$ outro?

\section{7. Familismo, gênero e política, ou a democracia brasileira e suas transições}

Qual o peso e a influência que a família e as relações familiares têm sobre as carreiras políticas e as chances de elegibilidade dos candidatos? Em que medida a esfera da vida privada interfere como impulso ou como obstáculo para a política? E em que medida isso é perpassado pelo gênero? Para efeito de análise, consideramos algumas questões já apresentadas em itens anteriores, na sua relação com outro conjunto de perguntas ainda não discutidas ${ }^{24}$.

Como mostrado, mais homens do que mulheres têm parentes que foram políticos. Isso ocorre também entre os eleitos. Nos aspectos da trajetória pessoal, já discutidos em bloco anterior, ter familiares políticos ficou em quarto lugar entre os homens, ao passo que, entre as mulheres, sua frequência ocupou o sétimo lugar.

Em se tratando de apoios individuais, familiares e parentes foram as principais menções entre os que responderam ter recebido apoio de outras pessoas. Entre aqueles que responderam sentir "resistência à candidatura", o traço de gênero mostrou-se expressivo, ainda que em um universo pequeno. Quase um quarto das mulheres mencionaram "familiares e parentes como principais agentes da resistência” às campanhas. Entre os homens tais respostas não chegaram a um décimo. $\mathrm{O}$ fato de, nesse tópico, as menções femininas serem sistematicamente mais elevadas merece uma reflexão mais acurada.

A resposta (negativa) ao tipo de reação da família à candidatura é aparentemente contraditória, já que, paralelamente, a família surge como a principal base

\footnotetext{
23 A eleição de 2012 foi a primeira, em 16 anos de implantação de cotas, na qual os $30 \%$ de candidaturas femininas foram alcançadas. Essas, porém, são eleições municipais e os índices já eram sistematicamente mais altos do que para os outros níveis.

24 Algumas são mais representativas porque são excludentes ou "ranquedas" e envolvem toda a amostra, ao passo que outras são derivadas de uma alternativa anteriormente escolhida e, portanto, de universos muito pequenos que, não obstante, podem servir como indicativos para novas perguntas de investigação.
} 
de apoio fora do âmbito do partido. Três em cada cinco entrevistados $(63 \%)$ receberam apoio integral dos familiares. Contudo, é mais uma vez emblemático que o percentual de apoio recebido integralmente pelos familiares seja ligeiramente maior entre os homens $(65 \%)$ do que entre as mulheres $(57 \%)$. Em contrapartida, $17 \%$ das mulheres informaram que enfrentaram resistências por parte dos familiares, enquanto entre os homens esse percentual foi de apenas $4 \%$. Ou seja: o cônjuge surge como o familiar que mais interfere negativamente no apoio dado ao candidato. E os filhos aparecem em seguida, como um familiar que resiste à candidatura dos pais. No universo minoritário dos que informaram ter sofrido resistência explícita, são os maridos que resistem bem mais do que as esposas. $\mathrm{O}$ traço de gênero é também perceptível nas distinções das razões para a resistência: entre as mulheres, sete em cada dez escolheram a opção "perda de tempo para a família" como possível razão. Entre os homens, apenas dois em cada dez fizeram essa escolha. E a maior parte atribuiu o motivo da resistência familiar à avaliação de falta de recursos financeiros.

Para um grande contingente da amostra, a vida familiar e responsabilidades domésticas impedem uma maior dedicação à política. Mas é surpreendente que o peso maior, como fator impeditivo para a dedicação à política, surja mais da parte dos homens $(53,4 \%)$ do que das mulheres $(45,8 \%)$. Trata-se de uma percepção que tanto pode ser interpretada como um empecilho concreto, de tempo ou veto, como um peso dado por cobranças familiares. Assim, há que se considerar a hipótese de que a natureza do empecilho possa ser pensada de maneira diferenciada para homens e mulheres, a depender do lugar de onde se observa. Enquanto os homens podem ter em mente algo mais próximo de uma percepção em relação ao outro e não a si próprio (o "outro" como sua esposa, por exemplo), podemos pensar que as mulheres, de alguma forma, estão falando de si próprias e de suas experiências. E isso, de certa forma, sugere-nos que as mulheres que vivenciam a experiência da vida política não a percebem com essa intensidade negativa que às vezes supomos. O lugar socialmente construído pode gerar, de outros, demandas e cobranças e a família parece ser um lugar privilegiado. Contudo, qual a natureza desse lugar e seus deslocamentos são questões a pensar-se, à luz de outras pesquisas existentes e de futuras investigações.

\section{III.8. Para qual eleitor e com que conteúdos falam as mulheres? As percepções sobre representação e os tipos de propostas}

As perguntas selecionadas neste bloco tiveram por intuito tentar captar as principais concepções sobre a natureza e o sentido da "representação" e como tais concepções expressam-se nas propostas de campanha de candidatos e candidatas. Sabemos que o problema da representação envolve questões polêmicas e complexas e sobre as quais não existe muito consenso político e acadêmico (KROOK \& CHILDS, 2010). Ao mesmo tempo, parte do debate sobre as razões para a defesa de ações afirmativas para as mulheres, particularmente sobre cotas e paridade, sustenta-se em justificativas que acionam, de algum modo, as dimensões descritiva, substantiva e simbólica da representação. O exame da literatura, seja ele de cunho mais teórico, seja empírico, indica certa lógica "essencialista" em muitas das razões aventadas para as mulheres estarem mais representadas no parlamento (SKJEIE \& SILM, 2000). Nesta seção, procuramos identificar o que pensam os entrevistados em relação a essas questões. Em seguida, tentamos pensar suas respostas em articulação com as outras dimensões analisadas ${ }^{25}$.

Entre os entrevistados tende a prevalecer uma percepção mais universal da representação. Tomando Phillips (1995) como referência, podemos sugerir que predomina uma concepção mais próxima da "política de ideias" do que da "política de presença"26. Isso porque, na ordem de escolhas sobre o que acredita que representaria na Câmara, a primeira opção das mulheres foi a representação de ideias, de interesses e povo em geral $(70 \%)$, assim como a dos homens (76\%). Mas enquanto mulheres escolheram como segunda opção "grupos de pessoas" - idosos, jovens, entre outros (66\%), entre os homens estão "grupos de interesses" - trabalhadores e grupos empresariais (51\%). Há certo equilíbrio entre os papéis de "representação de leis", em primeiro lugar, seguido de papel de "fiscalização" e, por fim, o de "representação dos interesses do grupo" ao qual o candidato está vinculado. Um pouco mais de homens em comparação com as mulheres mencionou a representação de grupos de interesse, mas em ambos esse tipo de representação não surge como tema central, o que é interessante se compararmos a outros países de democracia consolidada, sejam eles liberais, sejam com tradição mais republicana ${ }^{27}$.

\footnotetext{
25 Lembrando sempre que muitas das questões são de múltipla escolha.

26 A formulação de "política de ideias" e de "política de presença" é de Phillips (1995), e tem servido como uma importante referência para a literatura. Política de ideias baseia-se mais nas propostas do representante, ou seja, o quê o representante representa, ao passo que política de presença tem como importante referência as características, ou seja, quem é o representante.

27 Cabe destacar que pesquisas anteriores identificam uma elevada proporção de ações femininas no Congresso no âmbito da legislação, ou seja, apresentação de leis. Ver, por exemplo, Miguel e Birolli (2010).
} 
Confirmando outras pesquisas sobre conteúdos programáticos e agenda legislativa, entre as mulheres, os temas da saúde e da educação são os que vêm em primeiro lugar e com igual peso, seguido, com elevada distância, de direitos das mulheres e qualificação profissional. Entre os homens, o problema do emprego ocupa lugar destacado, seguido de temas ligados a desenvolvimento e infraestrutura, seguridade social, meio-ambiente e defesa dos idosos. Chama atenção, particularmente, a pequena ênfase dada pelas candidatas à questão do emprego, sobretudo se considerarmos o fato de que os maiores índices de desemprego estão entre as mulheres. Nota-se que a agenda masculina distribui-se mais em um número maior de tópicos e é mais diversificada, englobando temas de economia, infraestrutura, políticas social e agenda política. Prosseguiremos com essa análise, mais dirigida. Para o momento, vale indicar a importância de pensarmos sobre as consequências desse fato para o campo da disputa política e o que é ou não relevante e por quê.

\section{III.9. Mulheres na politica e estratégias de ingresso: opiniões e informações}

Aqui são apresentadas perguntas que dão prosseguimento ao item anterior, agora mais dirigido para as mulheres, entendidas como atrizes políticas. Os focos foram: as percepções de gênero existentes entre os candidatos quanto ao campo da política; as opiniões dos candidatos sobre as possíveis diferenças de estilos de acordo com o sexo e posições e avaliações sobre iniciativas e estratégias destinadas a ampliar o ingresso de mulheres na política. Um aspecto privilegiado para análise foi a adoção de cotas para candidaturas, especialmente porque, nas eleições de 2010, foi a primeira vez que a nova Lei de Cotas foi adotada. Interessava-nos, portanto, comparar as informações com a lei anterior e saber como a mais recente foi recebida, percebida e usada pelos candidatos e partidos.

A maioria dos entrevistados conhecia a Lei de Cotas estabelecida em 2007 (70\%). Não há diferenças significativas no conhecimento entre homens e mulheres, embora os percentuais sejam ligeiramente mais elevados para as mulheres. Os candidatos dos partidos pequenos são os que menos conhecem a lei e os dos partidos grandes são os que mais a conhecem. Praticamente seis em cada dez entrevistados não tinham conhecimento da versão recente, ou seja, a aprovada em 2009. O desconhecimento é maior entre os entrevistados homens, mais novos, menos escolarizados e membros de partidos com menor representação parlamentar. Apenas dois em cada dez candidatos dos partidos pequenos conhecia a nova lei. Para quem não conhecia, após estímulo da pergunta, mais de sete em cada dez entrevistados mencionaram ter conhecimento, mas foram principalmente as mulheres que responderam positivamente. Em geral, há uma avaliação positiva da maior parte dos candidatos em relação à existência das cotas $\mathrm{A}$ maioria das mulheres respondeu que a lei de cotas foi um motivo de debate na nomeação das candidaturas no interior dos partidos. Assim como em outras pesquisas, também se constatou que a maioria das mulheres não considera que sua candidatura tenha relação com a lei (60\%), embora o universo dos que responderam afirmativamente não seja desprezível.

Parece existir um grau razoável de disseminação de ações afirmativas nos partidos, já que praticamente metade dos entrevistados fez essa referência. Tais políticas foram mais confirmadas para jovens, negros e mulheres. A maioria vê essas políticas de maneira positiva, principalmente as mulheres e os mais jovens. As razões principais foram associadas com as opções "favorecer o debate sobre questões de gênero" e a "sub-representação feminina" no partido. Para a maior parte dos entrevistados, o partido tem histórico, organização ou militância de mulheres. As mulheres e os candidatos dos partidos com maior representação legislativa são os que mais percebem ações dessa natureza. Cursos de formação e políticas de ação afirmativa foram relatados por um numero razoável, porém, como foi aventado, não parecem guardar relação com quem se elege ou de fato disputa, ou seja, essas formas de investimento tenderiam a ser secundárias.

Em todas as questões associadas à igualdade de sexo ou à discriminação por gênero, os homens apareceram acreditando-percebendo mais a existência de igualdade do que as mulheres. A maior parte não percebe que existam diferenças de tratamento para homens ou mulheres na conduta ou nas práticas no interior da estrutura partidária. E isso corresponde a $70 \%$ entre as mulheres e $73 \%$ entre os homens. Para ambos os sexos, há uma percepção maior de diferença no tratamento de acordo com a renda e o poder econômico dos membros do partido. Contudo, em se tratando dos "estilos de fazer política", homens e mulheres discordam bastante: $76 \%$ das mulheres concordam em parte ou completamente que há diferenças e só $4,5 \%$ concordam que tais diferenças não existem. Entre os homens, apenas $38 \%$ concordam que haja estilos diferenciados de política de acordo com o sexo. Mas distintamente das mulheres, consideram mais a diferença no "foco de interesse político" (41\%) em comparação com mulheres que mencionaram tal foco $(39 \%)$.

Predominou a percepção de que as dificuldades para conseguir financiamento de campanha são iguais para homens e mulheres, mas essa opinião foi mais 
forte entre os homens (67\%) do que entre as mulheres (61\%). Entretanto, o percentual de candidatas que avaliam isso ser mais difícil para as mulheres não pode ser considerado desprezível (34\%). Ao lidarmos com a percepção e compararmos com dados de financiamentos declarados e analisados no âmbito do Consórcio, constatamos claramente as diferenças entre a "percepção" e as "práticas efetivas"28. Os dados do TSE indicam um diferencial no volume e nos tipos de financiamento de acordo com o sexo que permitem falar de maiores dificuldades para as mulheres. O financiamento de campanha é um item importante nas chances eleitorais e as próprias chances de obtenção de recursos volumosos são mediadas pelo gênero, conforme mostraram os estudos de Sacchet e Speck (2012) e Speck e Sacchet (2012a), no âmbito do Consórcio.

Candidatos e candidatas tenderam a não acreditar que as mulheres possam ser favorecidas por sua condição de sexo em disputas políticas (respectivamente $82,4 \%$ e $62,6 \%$ ). Contudo, entre aqueles que acreditam em tal possibilidade, há construções de gênero distintas de acordo com o sexo. Os tipos prevalecentes de "diferenças que beneficiariam as mulheres" mais citados pelos homens foram associados a uma construção social de gênero que coloca a mulher em um lugar de pureza feminina, externalidade e moralidade na política: $46,6 \%$ escolheram "honestidade" e "serem menos corruptas", seguidos de $36,8 \%$ que escolheram "sensibilidade e sentimentalismo". Já as mulheres, embora também com opções não desprezíveis por estereótipos de gênero semelhantes, parecem identificar-se com aspectos que afirmem suas capacidades como políticas, ressaltando as opções de "agressividade e combatividade (32,8\%), "embelezam a campanha" (21\%) e "propostas" (16\%).

Os principais obstáculos para uma maior igualdade na política, mencionados por todos os candidatos, mas bem mais pelas candidatas foram, por ordem de citações: (i) preconceito contra as mulheres em geral; (ii) mulheres são menos atuantes que os homens; (iii) gap entre avanços no mercado de trabalho e na política e (iv) responsabilidades familiares implicando redução de tempo para a família.

Os achados descritos acima apontam-nos reforços de algumas características e tendência, e permitemnos ampliar conclusões antes circunscritas a estudos de caso ou baseadas em um número de variáveis limitado. Um registro a ser feito é a maior proximidade

\footnotetext{
28 Isso pode ser visto no item seguinte, assim como nos trabalhos de Sacchet e Speck (SACCHET \& SPECK, 2012; SPECK \& SACCHET, 2012a), já citados.
}

entre as características encontradas entre os eleitos, independentemente de seu sexo, e as características ou recorrências positivamente associadas com os homens. Mas como interpretá-los de forma não só descritiva? No item seguinte tentamos fazer isto através de da análise de cluster.

\section{III.10. Análise de cluster}

Como indicamos, a fim de obter maior consistência analítica, decidimos explorar essa e outras associações com base em um modelo analítico de cluster que nos permitiria encontrar ou não proximidades e confirmar a análise.

Visando classificar os candidatos quanto ao perfil e a trajetória política, empregamos a técnica de análise de agrupamentos ou de clusters. Segundo Hair et alii (1998), esse tipo de análise é um conjunto de técnicas estatísticas cujo objetivo é agrupar objetos. Em nosso caso, estamos agrupando candidatos, segundo um conjunto de variáveis, para formar grupos ou clusters homogêneos. Os candidatos (objetos) em cada cluster tendem a ser semelhantes entre si, e diferentes dos demais que compõem os outros clusters. Esses clusters devem apresentar tanto uma homogeneidade dentro dele, como uma heterogeneidade entre eles.

Como o objetivo da análise de cluster é agrupar candidatos semelhantes, é necessária uma medida da distância entre os mesmos. Os candidatos com menor distância entre si são mais semelhantes, logo estarão em um mesmo cluster. Já os mais distantes compõem clusters distintos. Existem diferente maneiras de medir a distância entre os candidatos, como, por exemplo, o coeficiente de correlação, porém, a mais utilizada é a distância euclidiana entre os pontos.

Segundo Malhotra (2001), existem dois tipos de procedimentos de aglomeração: hierárquico e não hierárquico. $\mathrm{O}$ procedimento hierárquico caracterizase pela construção de uma hierarquia ou estrutura em forma de árvore, podendo ser "aglomerativa" ou "divisiva". Por sua vez, o procedimento não hierárquico, também chamado de $K$-means clustering, determina os centros dos clusters e em seguida agrupa todos os candidatos em um número pré-estabelecido de clusters, segundo uma distância desse centro.

Neste estudo, utilizaremos os dois processos de aglomeração. Iniciaremos com o procedimento hierárquico, por meio do método de Ward ${ }^{29}$. Nesse

29 Esse é um método de variância, derivado de um processo hierárquico e aglomerativo. No método de Ward, os clusters são gerados de tal maneira a minimizar a variância dentro do cluster, com o objetivo de minimizar o quadrado da distância euclidiana às médias dos clusters. 
procedimento aglomerativo, cada candidato tem início em um cluster separado. Em seguida, os clusters são formados agrupando-se os candidatos em clusters cada vez maiores. Em outras palavras, esse método agrupa os candidatos em função da informação existente, de modo que os candidatos de um grupo sejam tão semelhantes entre si quanto possível, quando comparados aos candidatos que formarão os grupos restantes.

O método de Ward possibilita visualizar os clusters em uma estrutura conhecida como dendograma (Anexo III). O dendograma é um gráfico hierárquico que deve ser lido da esquerda para a direita, onde as linhas verticais representam os clusters unidos e as linhas horizontais a distância euclidiana entre os mesmos. A partir desse gráfico, pode-se decidir sobre o número de clusters. No nosso caso, pode-se verificar a existência de três clusters.

Em um segundo momento, após a definição do número de clusters, utilizamos o procedimento não hierárquico (K-means) para melhor defini-los, seguindo os passos propostos por Hair (1998) e Romesburg (1990). Nesse procedimento são definidos os centros dos clusters e em qual cada candidato pertencerá, conforme visto no dendograma (Anexo III). Os participantes agrupados em cada um dos aglomerados mostraram distintas trajetórias pessoais e políticas (Tabela 1).

TABELA1_FREQÜÊNCIAE PORCENTAGEM DOSPARTICIPANTES NOS CLUSTERSPOR VARIÁVEIS

\begin{tabular}{|c|c|c|c|c|c|c|c|}
\hline \multirow[t]{2}{*}{$\square$} & & \multicolumn{2}{|c|}{ Cluster 1} & \multicolumn{2}{|c|}{ Cluster 2} & \multicolumn{2}{|c|}{ Cluster 3} \\
\hline & & Freq. & $\%$ & Freq. & $\%$ & Freq. & $\%$ \\
\hline \multirow[t]{2}{*}{ Resultado Eleição } & Eleito & 0 & 0,0 & 0 & 0,0 & 254 & 38,5 \\
\hline & Não Eleito & 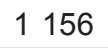 & 100,0 & 1236 & 100,0 & 406 & 61,5 \\
\hline \multirow[t]{2}{*}{ Sexo } & Masculino & 1007 & 87,1 & 869 & 70,3 & 606 & 91,8 \\
\hline & Feminino & 149 & 12,9 & 367 & 29,7 & 54 & 8,2 \\
\hline \multirow[t]{4}{*}{ Faixa Etária } & De 18a 39anos & 646 & 55,9 & 432 & 35,0 & 73 & 11,1 \\
\hline & De 40 a 49anos & 185 & 16,0 & 287 & 23,2 & 151 & 22,9 \\
\hline & De 50 a 59 anos & 202 & 17,5 & 317 & 25,6 & 92 & 13,9 \\
\hline & 60 ou mais & 123 & 10,6 & 200 & 16,2 & 344 & 52,1 \\
\hline \multirow[t]{3}{*}{ Estado Civil } & Solteiro(a) & 427 & 36,9 & 564 & 45,6 & 124 & 18,8 \\
\hline & Casado(a)/comp.(a) & 525 & 45,4 & 352 & 28,5 & 194 & 29,4 \\
\hline & Outros & 204 & 17,6 & 320 & 25,9 & 342 & 51,8 \\
\hline \multirow[t]{3}{*}{ Posição } & Político-Deputado Federal & 0 & 0,0 & 0 & 0,0 & 13 & 2,0 \\
\hline & $\begin{array}{l}\text { Político-Outros cargos } \\
\text { políticos }\end{array}$ & 33 & 2,9 & 104 & 8,4 & 416 & 63,0 \\
\hline & Outras atividades & $1 \sqcup 123$ & 97,1 & 1132 & 91,6 & 231 & 35,0 \\
\hline \multirow[t]{3}{*}{ Tamanho do Partido } & Partidos Grandes & 165 & 14,3 & 454 & 36,7 & 323 & 48,9 \\
\hline & Partidos Médios & 366 & 31,7 & 236 & 19,1 & 11 & 1,7 \\
\hline & Partidos Pequenos & 625 & 54,1 & 546 & 44,2 & 326 & 49,4 \\
\hline \multirow[t]{3}{*}{ Tempo filiado ao partido } & Até 2 anos & 545 & 47,1 & 238 & 19,3 & 374 & 56,7 \\
\hline & De 2 a 5 anos & 213 & 18,4 & 311 & 25,2 & 27 & 4,1 \\
\hline & Mais de 5 anos & 398 & 34,4 & 687 & 55,6 & 259 & 39,2 \\
\hline \multirow{3}{*}{$\begin{array}{l}\text { Motivos políticos que } \\
\text { levaram a lançar como } \\
\text { candidato }\end{array}$} & Militância e vontade própria & 351 & 30,4 & 736 & 59,5 & 411 & 62,3 \\
\hline & Convite do partido & 61 & 5,3 & 217 & 17,6 & 47 & 7,1 \\
\hline & $\begin{array}{l}\text { Participação em organização } \\
\text { e/ou proposta de movimentos } \\
\text { sociais }\end{array}$ & 530 & 45,8 & 89 & 7,2 & 7 & 1,1 \\
\hline
\end{tabular}




\begin{tabular}{|c|c|c|c|c|c|c|c|}
\hline & $\begin{array}{l}\text { Proposta ou motivação } \\
\text { familiar }\end{array}$ & 104 & 9,0 & 72 & 5,8 & 27 & 4,1 \\
\hline & Já ser ou ter sido parlamentar & 18 & 1,6 & 33 & 2,7 & 158 & 23,9 \\
\hline & Outras & 92 & 8,0 & 89 & 7,2 & 10 & 1,5 \\
\hline \multirow[t]{7}{*}{$\begin{array}{l}\text { Aspectos da trajetória } \\
\text { pessoal }\end{array}$} & $\begin{array}{l}\text { Representatividade eleitoral } \\
\text { ou partidária }\end{array}$ & 173 & 15,0 & 192 & 15,5 & 165 & 25,0 \\
\hline & $\begin{array}{l}\text { Experiência ou } \\
\text { representatividade pública }\end{array}$ & 31 & 2,7 & 713 & 57,7 & 54 & 8,2 \\
\hline & Vínculos associativos & 803 & 69,5 & 317 & 25,6 & 60 & 9,1 \\
\hline & Vínculos familiares & 59 & 5,1 & 2 & 0,2 & 6 & 0,9 \\
\hline & Motivações ideológicas & 0 & 0,0 & 0 & 0,0 & 311 & 47,1 \\
\hline & Outros & 0 & 0,0 & 0 & 0,0 & 47 & 7,1 \\
\hline & NS/NR & 90 & 7,8 & 12 & 1,0 & 17 & 2,6 \\
\hline \multirow{4}{*}{$\begin{array}{l}\text { Tempo de política } \\
\text { partidária }\end{array}$} & Até 2 anos & 76 & 6,6 & 68 & 5,5 & 21 & 3,2 \\
\hline & $3 \mathrm{a} 4 \mathrm{anos}$ & 438 & 37,9 & 109 & 8,8 & 38 & 5,8 \\
\hline & 5 a 9 anos & 54 & 4,7 & 119 & 9,6 & 78 & 11,8 \\
\hline & Mais de 10 anos & 588 & 50,9 & 940 & 76,1 & 523 & 79,2 \\
\hline \multirow{3}{*}{$\begin{array}{l}\text { Receita Declarada } \\
\text { da Campanha }\end{array}$} & Mais de $\mathbb{R} \$ 1$ milhão & 0 & 0,0 & 2 & 0,2 & 149 & 22,6 \\
\hline & De $\mathbb{R} \$ 100$ mil $\mathbf{a} \mid \mathrm{R} \$ 1$ milhão & 238 & 20,6 & 118 & 9,5 & 120 & 18,2 \\
\hline & Até $\mathrm{R} \$ 100 \mathrm{mil}$ & 918 & 79,4 & 1116 & 90,3 & 391 & 59,2 \\
\hline
\end{tabular}

FONTE: Os autores.

Já tendo definido os clusters e os candidatos que compõem cada um deles através do procedimento $K$ means, podemos interpretar o perfil desses clusters. Detalhando cada um, encontramos as seguintes características.

Cluster 1: chamamos de "iniciantes na política" por predominar os mais jovens $(55,9 \%$ com 18 a 39 anos), de partidos pequenos $(54,1 \%)$, com pouco tempo na política $(49,1 \%$ com menos de dez anos na política), com poucos recursos para a campanha (nenhum candidato com receita declarada acima de R \$ 1 milhão), com vínculos associativos na trajetória pessoal $(69,5 \%)$ e cujo motivo para lançar-se a candidato era a participação em organização e/ou movimentos sociais $(45,8 \%)$.

Cluster 2: chamados de "homens e mulheres não eleitos" é o maior grupo. Quando comparado aos outros dois clusters, esse grupo possui uma representatividade maior de mulheres $(29,7 \%)$; é formado por solteiros $(45,6 \%)$; tem mais de 5 anos no partido $(55,6 \%)$ e mais de dez anos na política partidária $(76,1 \%)$; baixos recursos para a campanha $(90,3 \%$ com até $\mathrm{R} \$ 100$ mil) e representatividade pública na trajetória pessoal $(57,7 \%)$.
Cluster 3: chamados de "potenciais eleitos": é o menor grupo, onde estão todos os candidatos eleitos. Esse cluster é formado por maioria de homens $(91,8 \%)$; candidatos mais velhos $(52,1 \%$ com mais de 60 anos); tem mais de dez anos na política $(79,2 \%)$; tem todos os candidatos à reeleição entrevistados na pesquisa, tendo como motivação lançarem-se candidatos e já serem ou terem sido parlamentares $(62,3 \%$ e $23,9 \%$, respectivamente) e com mais receita para a campanha (22,6\% com mais de R $\$ 1$ milhão).

\section{CONCLUSÕES}

Embora as respostas dos entrevistados e as recorrências encontradas não possam ser objeto de generalização, elas apontam-nos e sugerem padrões. Alguns já são comprovados, ao passo que outros surgem como indicativos para investigações posteriores. A análise de cluster, por sua vez, ajudounos a identificar de maneira mais precisa as proximidades desses perfis, trajetórias e potencialidades de elegíveis. Podemos destacar alguns pontos centrais relacionados com a "oferta" no processo eleitoral; esta passa por certas trajetórias, recursos e determinadas relações entre os candidatos e os partidos. 
Liderança pessoal, associativismo, vida pública e envolvimento com grupos de interesse tenderam a ser relevantes e podem ser aspectos associados com padrões de ingresso. Coerente com o peso da religião no país, o apoio da Igreja surge como um dos mais importantes. Redes de apoio são veículos importantes para a propagação das campanhas, mas as redes institucionais impessoais são mais mencionadas pelos homens, ao passo que as sociais foram-no pelas mulheres. Cargos e trajetórias públicas, assim como bases locais, são outras formas que aparecem como importantes canais formadores de capitais prévios para as candidaturas. A ocupação de espaços públicos associados com o exercício de alguma forma de poder parece, portanto, ser um traço de gênero que interage com estímulos e disposições para a disputa eleitoral e, ao que tudo indica, aumenta o potencial de elegibilidade. Pode-se, portanto, falar que as trajetórias de experiências públicas constituem formas importantes de recursos não financeiros. E os homens tendem sistematicamente a deter mais recursos do que as mulheres, corroborando a mencionada observação de Chapman (1993). O histórico de familiares na política pode favorecer mais quem ingressa e disputa um cargo, mas tais históricos estão menos presentes entre as mulheres. Ter familiares políticos ficou em quarto lugar entre os homens, ao passo que entre as mulheres sua freqüência ocupou o sétimo lugar. Esse item pode ser um indicativo de como o parentesco pode operar como um capital político positivo para recrutamento e ingresso. Por outro lado, cabe pensar na possibilidade de que a família venha enfraquecendo-se como recurso e canal de ingresso político à medida que seus padrões modificamse e o país amplia a dimensão institucional das organizações, hipótese a ser bem mais explorada futuramente.

Questões decisivas do que denominamos como "engenharia eleitoral" não são conhecidas pela maior parte dos entrevistados, mas entre os eleitos são bem conhecidas. Os dados corroboram a já comprovada maior familiaridade masculina com os partidos. Há uma diferença interessante entre as respostas por sexo, que remete a percepções distintas dos caminhos e meandros por onde se constrói o recrutamento e essa engenharia. As principais menções sobre os processos de tomada de decisões sobre formação de chapas partidárias e de candidaturas eleitorais revelam uma diferença entre a percepção de homens e mulheres. Homens percebem mais pragmaticamente esses processos, ao passo que as mulheres tendem a uma compreensão mais formal, sugerindo, na prática, um conhecimento menor e, portanto, parecendo idealizá-los mais do que os homens. O domínio da engenharia eleitoral e a inserção na tomada de decisões podem ser importantes, também, diante da diversidade de respostas que não aponta para um tipo específico de recrutamento, mas sugere a importância de vários caminhos e contextos. Em outros termos, podemos sugerir dois tipos de domínio ou conhecimento eleitoral: um domínio aparente e um domínio efetivo, associados à natureza mais ou menos formal ou pragmática do processo. Neste caso, as mulheres parecem ter um domínio mais aparente e os homens um domínio mais efetivo.

Considerando achados anteriores da literatura bem como o conjunto de respostas desta pesquisa, é possível sugerir que ser dirigente partidário pode ser um importante estímulo e base para a disputa eleitoral ${ }^{30}$.

Homens e mulheres revelam padrões de satisfação ou insatisfação parecidos, mas as mulheres mostraramse mais satisfeitas com o apoio do partido. Trata-se de um dado surpreendente e que contraria muitas percepções sobre essa relação. Reiteramos a possibilidade considerada mais acima: tais respostas dadas pelas mulheres, mais do que apoio, revelariam desconhecimento ou baixa expectativa em relação à sua própria candidatura. A primeira em relação à engenharia efetiva que é necessária para uma campanha com alguma chance de sucesso. A segunda porque parte dessas candidaturas não tinha um intuito de competir; de fato, apoio recebido por mulheres adquiriria uma dimensão simbólica talvez maior do que seu peso real. Outras questões a serem mais bem investigadas.

$\mathrm{Na}$ pesquisa, os partidos mais institucionalizados (em geral os maiores) são os que oferecem bases mais consistentes de campanha. Os menores surgem como os menos formalizados, mais precários e, também, com listas de candidaturas mais "pró-forma", ou seja, apenas para constar. Já os médios apresentam algumas características interessantes que nos permitiriam explorar a seguinte hipótese: os partidos médios surgem como relevantes para futuros estudos porque parecem apresentar maiores pontos de tensão, mais domínio de informações por parte dos candidatos e mais insatisfação. Em outros termos, quem de fato está tentando ingressar sem muitos recursos e capitais, mas com maior disposição para competir, estaria nesses partidos, de modo significativo.

Considerando que a resposta ao motivo de lançamento da candidatura como convite do partido é bem maior para as mulheres, é possível inferir que as cotas tendem a funcionar como entrada para uma parte das mesmas. Mas cotas e ações afirmativas surgem como algo mais que residual no recrutamento, portanto,

\footnotetext{
30 Entre os 19 eleitos da base de dados sem expansão, 16 ocupavam cargos no partido.
} 
não é possível concluir que joguem um papel decisivo, sobretudo na viabilidade da eleição.

Em resumo, o papel dos partidos surge como fundamental nas percepções e expectativas de apoio e estímulo às possíveis candidaturas. E embora muitos digam prescindir dos partidos, estes parecem operar como decisivos na viabilização eleitoral. Na média, os homens têm mais tempo de militância partidária do que as mulheres, embora o tempo de filiação destas não seja desprezível. Desse modo, se a inserção no partido conta, como estamos constatando, as mulheres já sairiam em desvantagens no processo eleitoral.

No quesito campanhas, redes institucionais de apoio surgem como importantes, e os homens tendem a mencioná-las mais. De maneira idêntica, mais recursos financeiros, mais acesso a outros tipos de recursos como, por exemplo, o HGPE e maior apoio partidário, são itens mais constantemente mencionados por candidatos do sexo masculino. E talvez porque disponham de menos recursos para outros tipos de campanha, certo perfil de campanha mais pessoal e menos institucional mostrou-se mais comum entre mulheres. Os dados sugerem que estas dependem mais das redes informais localizadas e do chamado "trabalho de base". Informações sobre a prestação de contas financeiras tenderam a confirmar essa maior informalidade das suas campanhas. Mais informal e financeiramente débil, na média, também tem menos acesso ao HGPE. Como vimos, familiares e parentes são os mais citados por ambos como apoios não institucionais, mas bem mais pelas mulheres. Podemos então sugerir que, em comparação com os homens, a maior satisfação encontrada da parte das mulheres revelaria, assim, menor expectativa ou desconhecimento ao ingressar na competição, e não, de fato, maior apoio partidário. Dado que os resultados são distintos, é possível pensar em elementos que mediam as situações e interferem nessa percepção: menor experiência das mulheres faz que exista uma percepção de apoio, provavelmente, superdimensionada. Outra hipótese é que, de fato, as pessoas sejam mais condescendentes, gentis, com as mulheres candidatas, embora isso não venha a reverterse em capitais efetivos, considerados estratégicos para ampliar a competitividade eleitoral. Entre as mulheres, os recursos mais pessoais, como o corpo a corpo, surgem como meios mais usuais de passar a mensagem, ao passo que entre os homens, os meios mais citados passam por exposições menos pessoais. Ou seja, parecem existir recursos de mais longo alcance, ou mais eficazes eleitoralmente à disposição dos homens, em comparação com as mulheres. A maior parte avalia que o dinheiro foi o fator decisivo para a não eleição e que impediu o seu desenvolvimento. Mas como veremos a seguir, não se trata, portanto, só de uma percepção: há uma forte interação com as probabilidades de um indivíduo ser eleito. E o impacto é efetivamente maior sobre as candidatas. Ou seja, há indícios, a serem mais bem explorados em pesquisas futuras, de que mulheres apresentam formas mais pessoais, delimitadas e sociais de apoio, ao passo que homens apresentam formas mais impessoais, institucionais e abrangentes. Em suma, é possível sugerir que há um diferencial de sexo quando falamos de um padrão mais consistente de campanha.

Há uma relação dúbia entre família e política para as entrevistadas. Como a rede pessoal, a família tem um papel, mas, em geral, ainda é um espaço bem mais adverso para as mulheres. Há um conjunto de valores ainda significativos que associa as mulheres ao "outro", em um mundo dos indivíduos e dos sujeitos. Ainda é forte a imagem da mulher como objeto do outro e não sujeito de si. E na família isso tende a aparecer mais, caso identificado nessa pesquisa. A família e o parentesco parecem operar, simultaneamente, como estímulo e como contenção de ingresso, mas esses dois movimentos tendem a ter pesos diferenciados, a depender do sexo do candidato ${ }^{31}$. Ou seja, por um lado parece favorecer os homens e, por outro, desfavorecer as mulheres em pontos estratégicos. Alguns indícios dessa possibilidade são, por exemplo, maior presença de familiares políticos e em cargos públicos entre os homens; assim como mais menção (embora residual) de estímulo para ingresso na política e para candidatar-se; as menções a apoios pessoais recebidos são mais fortes para as mulheres. Três em cada cinco entrevistados disse ter apoio integral de familiares, mas as maiores menções foram dos homens. A resistência de origem familiar é emblemática do que está sendo dito. No universo minoritário dos que informaram ter sofrido resistência explícita à candidatura, são os maridos que resistem bem mais do que as esposas. O traço de gênero é também perceptível nas distinções das razões para a resistência: entre as mulheres, sete em cada dez escolheram a opção

\footnotetext{
31 Faz-se necessário considerar o fato de que estamos trabalhando com uma amostra limitada em vários sentidos. E uma deles talvez tenha um impacto direto nesse conjunto de dados. Trabalhamos com 14 estados e duas regiões com representatividade amostral: Sul e Sudeste. Contudo, como se pode notar na composição dos estados, as regiões Nordeste, Norte e Centro-Oeste estão sub-representadas. Ocorre que são exatamente nessas regiões, talvez, sobretudo no Nordeste, que a literatura tem encontrado traços "familistas" mais fortes nas trajetórias, influências e reprodução da representação política via gerações de parentela. Com isso, pretendemos deixar claro que as observações, além de parcimoniosas, são também indicadoras de traços identificados para futuras pesquisas.
} 
"perda de tempo para a família". Uma em cada quatro mulheres citou a família como o "agente" da resistência. São os cônjuges os que mais manifestam resistência e, em seguida, os filhos, mas a proporção das menções à resistência do esposo é bem mais elevada do que a da resistência das esposas. Mulheres citaram, ainda, embora de modo bem residual, a resistência do pai e do tio, mas esse caso esteve ausente entre os homens. Ou seja, é possível sugerir que esses dois movimentos caminham juntos, mas tendem a operar de modo distinto: como elemento mais forte de contenção para as mulheres e de estímulo para os homens. Pode também ser lido como um indicativo dessa ambiguidade o fato de a percepção sobre a conciliação entre vida familiar e política ser menos negativa entre as mulheres. Assim, ainda que se constitua apenas em uma "pista", porque as informações são pouco significativas estatisticamente, uma vez experimentada a participação política mais ativa, é provável que elas não acreditem que a política interfira tanto quanto se supõe. Ou seja, o espaço privado das relações interpessoais constituirse-ia como um espaço de "contenção"32 para as mulheres, ao contrário dos homens. Pode-se acrescentar ainda a impressão de que o pessoal surge como feminino e o impessoal masculino, como em uma reprodução de outros padrões de gênero.

Nessa mesma linha, a presença feminina surge com uma aparência essencialista e naturalizada tanto por meio de sua agenda como nas percepções sobre diferenças de gênero na política. Não se podem subestimar os impactos sobre a visibilidade e o momento eleitoral. Entre mulheres, os temas, além de mais concentrados nas áreas típicas, são também mais associados com o "cuidado" e a "atenção". Se as razões para a sua presença, assim, tenderiam a entrelaçar os focos e as agendas prioritários com as características "femininas", as razões para homens não precisam ser postas ou justificadas porque têm sido, historicamente, a expressão ou personificação da representação. E como encarnação dessa representação, os temas "estratégicos", "estruturantes" da economia e/ou da política surgem-lhes, também, com aparência natural, intrínseca aos "temas masculinos". Aqui, permitimonos sugerir a existência do que definimos como uma "condensação programática" na agenda das mulheres, gerando uma espécie de estreitamento de mercado eleitoral. Tal estreitamento seria marcado por três aspectos que parecem operar desfavoravelmente: $(i)$ um número menor de candidatas; (ii) candidatas repetindo um mesmo leque de temas e (iii) candidatas repetindo tal leque em torno de dimensões pouco

\footnotetext{
32 Tomamos aqui emprestado o termo de Miguel (2009), nesse caso, para referir-se à própria política.
}

valorizadas na política. Ou, dito de outra forma, muitas mulheres disputando áreas discursivas idênticas, em geral mais "gastas" politicamente por serem entendidas como genéricas e consideradas menos importantes. Tratar-se-ia, também, de um discurso já associado a um "senso comum" eleitoral, portanto de poucos atrativos.

Um segundo aspecto que a análise permite sugerir é que o discurso das candidatas tende a falar às mulheres, sobretudo, como mães e como cuidadoras, e menos como sujeitos e indivíduos. Temas que as interessariam na condição de cidadãs e indivíduos, tais como emprego, são pouco tratados. Assim, uma questão a ser mais bem investigada é a de que poderia haver uma "contenção"33 na agenda das mulheres em torno de determinados temas, tratados e repetido por todas e de maneira exaustiva. Uma hipótese é a de que, ao lado de uma densidade de disputa circulando em torno desses conteúdos, isso poderia gerar um resultado de generalidade e banalização temáticas desfavoráveis às mulheres em uma campanha eleitoral.

As associações com papéis sexuais distintos e típicos para homens e mulheres, os quais são ressignificados na política, ainda são fortes entre os candidatos entrevistados. Da parte das mulheres, o essencialismo parece ser ainda forte e bastante arraigado. Tal essencialismo naturaliza seus lugares como "bons", em contraposição a um mundo político que se apresentaria como problemático. Isso, talvez, constitua-se em uma forma de conferir-lhes legitimidade na demanda por ingresso. E, da parte dos homens, persistem as idéias de "pureza" e de "menor agressividade", aspectos que, entretanto, não seriam muito favoráveis à disputa no mundo da política; um mundo contaminado por outros valores e dinâmicas. Podemos indicar que os homens tendem a ter uma percepção mais opaca das desigualdades do que as mulheres, fato natural diante das características das relações de gênero.

Voltar ou não a candidatar-se foi um fato considerado pela maioria dos que não se elegeram. Isso, por sua vez, pode ser um indicador de que a maior parte dos candidatos estava realmente disputando, independentemente de seu potencial eleitoral. E diz algo sobre as estratégias de mais longo prazo: para uma parte desses candidatos, embora sabendo das parcas chances eleitorais, a campanha seria mais uma preparação para futuras eleições e uma forma de fazerem-se conhecidos; recurso esse usado entre candidatos iniciantes. Ao mesmo tempo, como vimos,

\footnotetext{
33 Objeto de investigação sobre outro ângulo por Miguel e Birolli (2010).
} 
entre os que consideraram essa possibilidade, os homens fizeram-no bem mais do que as mulheres. E no caso de fazer-se conhecido no médio prazo, as mulheres estariam em desvantagem. Entre os que se elegeram, apoio e conhecimento partidário e já ter experiência eleitoral foram aspectos destacados.

Os três clusters encontrados ajudam-nos a confirmar características centrais que conformam os perfis e trajetórias daqueles que são potenciais elegíveis. Ao lado dos traços mencionados acima, ficam claras algumas variáveis que podem ser consideradas chave, já testadas em outros estudos e mais uma vez confirmadas aqui. $\mathrm{Na}$ análise de cluster, elas foram associadas, sobretudo, com o sexo masculino e com ter sido eleito. Ou seja, quando incluímos a característica de sexo do candidato, ser homem está associado com já ser ou ter sido parlamentar, estar tentando a reeleição, ter um tempo razoável de atuação política, possuir militância e ter gasto um valor relativamente elevado na campanha eleitoral.

Em outras palavras, a resposta para as campanhas de sucesso, sobretudo iniciais, pode estar ligada à trajetória política e às redes sociais nas quais essas mulheres estão inseridas. A tendência à inércia eleitoral dada pela chance de reeleição seria o desdobramento, ainda assim menos favorável às mulheres.

Em suma, no caso da Câmara dos Deputados, as estratégias para alcançar maior equilíbrio de sexo tenderiam a passar: $(i)$ pelos partidos, via consolidação de experiência partidária; (ii) por ocupação de cargos públicos; (iii) por formas de associação, de militância e de estruturação de redes ou representatividade pessoal e, sobretudo, (iv) pela disponibilidade de recursos financeiros, pessoais ou oriundos de redes e doações.

Clara Araújo (claramaria.araujo@gmail.com) é Doutora em Sociologia e Antropologia pela Universidade Federal do Rio de Janeiro (UFRJ) e Professora do Departamento de Ciências Sociais (DPCIS) e do Programa de PósGraduação em Ciências Sociais (PPCIS) da UERJ.

Doriam Borges (doriamb@gmail.com) é Doutor em Sociologia pelo Instituto Universitário de Pesquisas do Rio de Janeiro (IUPERJ). Professor do Departamento de Ciências Sociais (DPCIS) e do Programa de Pós-Graduação em Ciências Sociais (PPCIS) da UERJ.

\section{REFERÊNCIAS BIBLIOGRÁFICAS}

ALVARES, L. 2004. Mulheres na competição eleitoral, seleção de candidaturas e o padrão de carreira política no Brasil. Rio de Janeiro. Tese (Doutorado em Ciência Política). Instituto Universitário de Pesquisas do Rio de Janeiro.

ALVES, J. E. D. \& CAVENAGHI, S. M. 2005. $A$ mulher nas eleições de 2004: avaliação da política de quotas no Brasil. Trabalho apresentado no $25^{\circ}$ Congreso de la Asociación Latinoamericana de Sociología, realizado em Porto Alegre, de 22 a 26 agosto. Digit.

ANNE, P. 1995. The Politics of Presence. Oxford: Oxford University.

. 1998. Democracy and Representation: or why should it matter who our representants are? In: PHILliPS, A. (ed.). Feminism and Politics. Oxford: Oxford University.

ARAÚJO, C. 1998. Mulheres e representação política - a experiência das cotas no Brasil. Revista Estudos Feministas, Florianópolis, v. 6, n. 4, p. 7191. Disponível em: 150.162.1.115/index.php/ref/ article/download/12035/11312. Acesso em: 9.dez.2012.
1999. Cidadania incompleta: o impacto da lei de cotas sobre a representação política das mulheres no Brasil. Rio de Janeiro. Tese (Doutorado em Ciência Política). Universidade Federal do Rio de Janeiro.

2001. As cotas por sexo para a competição legislativa: o caso brasileiro em comparação com experiências internacionais. Dados, Rio de Janeiro, v. 44, n. 1, p. 155-195. Disponível em: http:// www.scielo.br/scielo.php? script= sci_arttext\&pid=S0011-52582001000100006. Acesso em: 28.jan.2013.

. 2009. Gênero e o acesso ao poder legislativo no Brasil: as quotas entre as instituições e a cultura. Revista Brasileira de Ciência Politica, Brasília, n. 2, p. 23-60, jul.-dez. Disponível em: http:// seer.bce.unb.br/index.php/rbcp/article/view/6626. Acesso em: 9.dez.2012.

(coord.). 2010. Consórcio Berta Lutz. Mulheres nas Eleições de 2010. Eixo II - Processos eleitorais e gênero. Relatório final. Secretaria Especial de Políticas para as Mulheres.

ARAÚJO, C. \& ALVES, J. E. D. 2007. Impactos de 
indicadores sociais e do sistema eleitoral sobre as chances das mulheres nas eleições e suas interações com as quotas. Dados, Rio de Janeiro, v. 50, n. 3, p. 535-577. Disponível em: http://www.scielo.br/ pdf/dados/v50n3/04.pdf. Acesso em: 9.dez.2012.

ARAÚJO, C. \& BORGES, D. 2012a. O gênero, os elegíveis e os não-elegíveis: uma análise das candidaturas para a Câmara Federal em 2010. In: ALVES, J. E. D.; PINTO, C. R. \& JORDÃO, F. (orgs.). As mulheres nas eleições de 2010. Rio de Janeiro: ABCP.

BOLOGNESI, B. \& COSTA, L. D. 2009. Estruturação social e enquadramento institucional no processo de formação das elites políticas: o caso da eleição de mulheres para a Câmara dos Deputados em 2006. Trabalho apresentado no I Seminário Intermediário da Associação Brasileira de Ciência Política, realizado em São Carlos, de 18 a 20 de novembro. Digit.

CHAPMAN, J. 1993. Politics, Feminism and Reformation of Gender. Londres: Routledge.

HAIR, J. F.; TATHAM, R. L.; ANDERSON, R. E. \& BLACK, W. 1998. Multivariate Data Analysis. 5a ed. New York: Prentice Hall.

KROOK, M. L. \& CHILDS, S. 2010. An Introduction. In: KROOK, M. L. \& CHILDS, S. (eds.). Women, Gender, and Politics. Oxford: Oxford University.

MACHADO, M. D. C. \& STEFFENON, R. 2011. Assimetrias de gênero nas campanhas eleitorais para a Câmara Federal. In: ARAÚJO, C. (coord.). 2010. Consórcio Berta Lutz. Mulheres nas Eleições de 2010. Eixo II - Processos eleitorais e gênero. Relatório final. Secretaria Especial de Políticas para as Mulheres.

MALHOTRA, N. K. 2001. Pesquisa de marketing: uma orientação aplicada. $3^{\mathrm{a}}$ ed. Porto Alegre: Bookman.

MARX, J.; BORNER, J. \& CAMINOTTI, M. 2007. Las Legisladoras. Cupo de Gênero y Politica en Argentina. Buenos Aires: Siglo XXI. Disponível em: http://www.artemisanoticias.com.ar/images/ FotosNotas/8PNUDLaslegisladoras.pdf. Acesso em: 9.dez.2012.

MIGUEL, L. F. 2003. Capital político e carreira eleitoral: algumas variáveis na eleição para o congresso brasileiro. Revista Sociologia e Política, Curitiba, n. 20, p. 115-134, jun. Disponível em: http:// www.scielo.br/pdf/rsocp/n20/n20a10.pdf. Acesso em: 9.dez.2012.

MIGUEL, L. F. \& BIROLI, F. 2009. Mídia e representação política feminina: hipóteses de pesquisa. Opinião Pública, Campinas, v. 15, n. 1, p. 55-81, jun. Disponível em: http://www.scielo.br/pdf/op/ v15n1/a04v15n1.pdf. Acesso em: 3.jan.2012.

NORRIS, P. 1993. Conclusion. In: NORRIS, P. \& LOVENDUSKI, J. (eds.). Gender and Party Politics. Londres: Sage.

NORRIS, P. \& LOVENDUSKI, J. 1996. Women Politicians: Transforming Westminster? In: NORRIS, P. \& LOVENDUSKI, J. (eds.). Women in Politics. Oxford: Oxford University.

SKJEIE, H. \& SILM, B. 2000. Scandinavian Feminist Debate on Citizenship. International Political Science Review, Thousand Oaks, v. 21, n. 4, p. 345-361.

SACCHET, T. \& SPECK, B. 2012. Participação feminina e dinâmica de campanha no HGPE nas eleições de 2010 para a Câmara dos deputados. In: ALVES, J. E. D.; PINTO, C. R. \& JORDÃO, F. (orgs.). As mulheres nas eleições de 2010. Rio de Janeiro: ABCP.

SPECK, B. \& SACCHET, T. 2012a. As eleições presidenciais de 2010: candidatas mulheres ou mulheres candidatas? In: ALVES, J. E. D.; PINTO, C. R. \& JORDÃO, F. (orgs.). As mulheres nas eleições de 2010. Rio de Janeiro: ABCP.

SPECK, B. \& SACCHET, T. 2012b. Patrimônio, instrução e ocupação dos candidatos: uma análise das candidaturas de mulheres e homens nas eleições gerais de 2010 no Brasil. Mimeo.

ROMESBURG, H. C. 1990. Cluster Analysis for Researchers. Krieger: Lulu. 


\section{ANEXOS}

I. PERGUNTAS DO QUESTIONÁRIO APLICADO AOS CANDIDATOS SELECIONADOS E AGREGADOS

1. Os entrevistados: perfil sociodemográfico e vínculos sociais.

2. Motivações que constroem caminhos da inserção partidária e eleitoral: $\mathrm{O}$ que o/a motivou a ingressar na carreira política? Quais as motivações políticas que o levaram a lançar-se ou a ser lançado candidato? Quais aspectos de sua trajetória pessoal foram mais importantes para chegar a disputar o cargo atual de Deputado Federal? Você diria que sua motivação principal deveu-se a um projeto pessoal ou a outras circunstâncias?

3. Outras formas de recursos: trajetórias e experiências públicas: algum (outro) familiar seu exerce ou exerceu um cargo público ou partidário nos últimos 30 anos? Já ocupou ou participou de direções e/ou cargos em alguma organização não partidária (acadêmica, em ONGs, organizações sindicais, profissionais ou movimentos sociais)? Já ocupou ou ocupa algum cargo na administração pública? Já ocupou ou ocupa algum cargo empresarial ou de representação fora de governo e que considere relevantes? Já ocupou cargos no poder Legislativo ou no poder Executivo?

4. Outros recursos: inserção e experiência partidária: quantos anos fazem que se dedica e participa da política partidária? Há quanto tempo é filiado a esse partido? Já ocupou ou ocupa algum cargo partidário? Além desta eleição, já tentou candidatar-se em outras eleições a mais de uma carreira parlamentar? Você sentiu alguma resistência à sua candidatura? Tem conhecimento sobre o processo de formação de chapas para dirigentes internos do seu partido? Se tem, como são tomadas as decisões, na prática, além do que define o estatuto? Sabe como é o processo de formação das chapas-listas eleitorais no seu partido? Se sabe, quais os critérios usados para formar ou construir a chapa, por ordem de importância e segundo a sua percepção? O que predominou na sua relação com o partido durante a campanha? Sabe como foram definidos os critérios de distribuição dos recursos do partido para os candidatos no período eleitoral? Entre os critérios apresentados, pode listar os três que considera serem prioritários, segundo a ordem de importância? Como avalia, em termos de satisfação, os recursos que você obteve do partido? Você sabe como foi definido o critério do seu partido para a distribuição do tempo no Horário Gratuito de Propaganda Eleitoral?

\section{Estratégias eleitorais e consistência de}

campanha: você realizou algum curso de formação de liderança política antes de disputar sua primeira eleição? Você sentiu alguma resistência à sua candidatura? Por parte de quem? Durante a campanha, diria que recebeu apoio mais do que esperado, esperado ou menos do que o esperado? Para o seu público e o seu tipo de campanha, qual/quais o(s) recurso(s) mais importante(s) para você passar a sua mensagem? De quais outros grupos (além do partido) recebeu apoio? Quais as formas em que se deu o apoio? Tem ideia de quantas vezes você apareceu na Propaganda Política Gratuita durante a campanha? Quanto tempo diário, em média, você dedicou às atividades de campanha? Pretende candidatar-se futuramente? Em sua opinião, quais os motivos principais que contaram para a sua eleição?

6. Familismo, gênero e política, ou a democracia brasileira e suas transições: algum familiar exerceu ou exerce um cargo público ou político partidário? Por parte de quem sentiu resistência à sua candidatura? Aspectos de sua trajetória pessoal que foram mais importantes para disputar o cargo de Deputado Federal? De quais outras pessoas recebeu apoio? Em relação à sua família, pode identificar o principal tipo de reação diante de sua candidatura? Neste caso, por parte de quem sentiu resistência? Quais as razões para tal resistência? Por que sua dedicação não foi exclusiva? Considera que a vida familiar e/ou a responsabilidade doméstica têm muito peso e impedem-lhe de dedicar mais tempo à política? Para que eleitor e com que conteúdos falam as mulheres?

7. As percepções sobre Representação e os tipos de propostas: caso fosse eleito(a), o que o(a) Sr.(a) pensaria em representar no Congresso? Como vê o seu papel de representante político? Quais os principais temas-propostas que o Sr.(a) defendeu em sua campanha? Nessas propostas, qual foram os temas específicos trabalhados?

8. Mulheres na política opiniões e informações: você conhece a Lei de Cota de 2007? E a sua versão recente de 2009? Você já ouviu falar da Lei de Cotas, que destina ao gênero feminino $30 \%$ das vagas disputadas para os cargos legislativos? Você avalia que sua candidatura tem alguma relação com a Lei de Cotas? Existe algum tipo de política de ação afirmativa no seu partido, isto é, voltada para fortalecer estimular um setor específico? Essa política foi dirigida para qual setor? Sabe se o seu partido tem história e organização e militância de mulheres, isto é, há práticas estruturadas de reuniões de diretórios, grupos e outras formas de militância? O cumprimento da nova lei de cotas por sexo para candidaturas a cargos de eleição proporcional 
foi ou não foi tema de discussão-mobilização no momento da nominação de candidatos no seio do seu partido? Na avaliação da participação-militância das mulheres no dia a dia das estruturas partidárias oficiais, percebe algum tipo de diferença por sexo? E nas seguintes situações: (i) frequência (ao partido); (ii) no tipo de atividade que exercem; (iii) nos focos de interesse políticos nos debates ou ação política; (iv) você acredita que as dificuldades-chances de conseguir financiamento desse setor (partido) são: (a) iguais para homens e mulheres; (b) mais difíceis para homens; (c) mais difíceis para mulheres? Considera que há diferenças de tratamento dos candidatos no partido que passem por questões como: (a) sexo; (b) idade; (c) renda e poder econômico? Acredita que há vantagens que favoreçam as mulheres na política? 
II. DENDOGRAMA DOS CANDIDATOS A DEPUTADO FEDERAL SEGUNDO O MÉTODO DE WARD. DISTÂNCIA EUCLIDIANA ENTRE OS CONGLOMERADOS

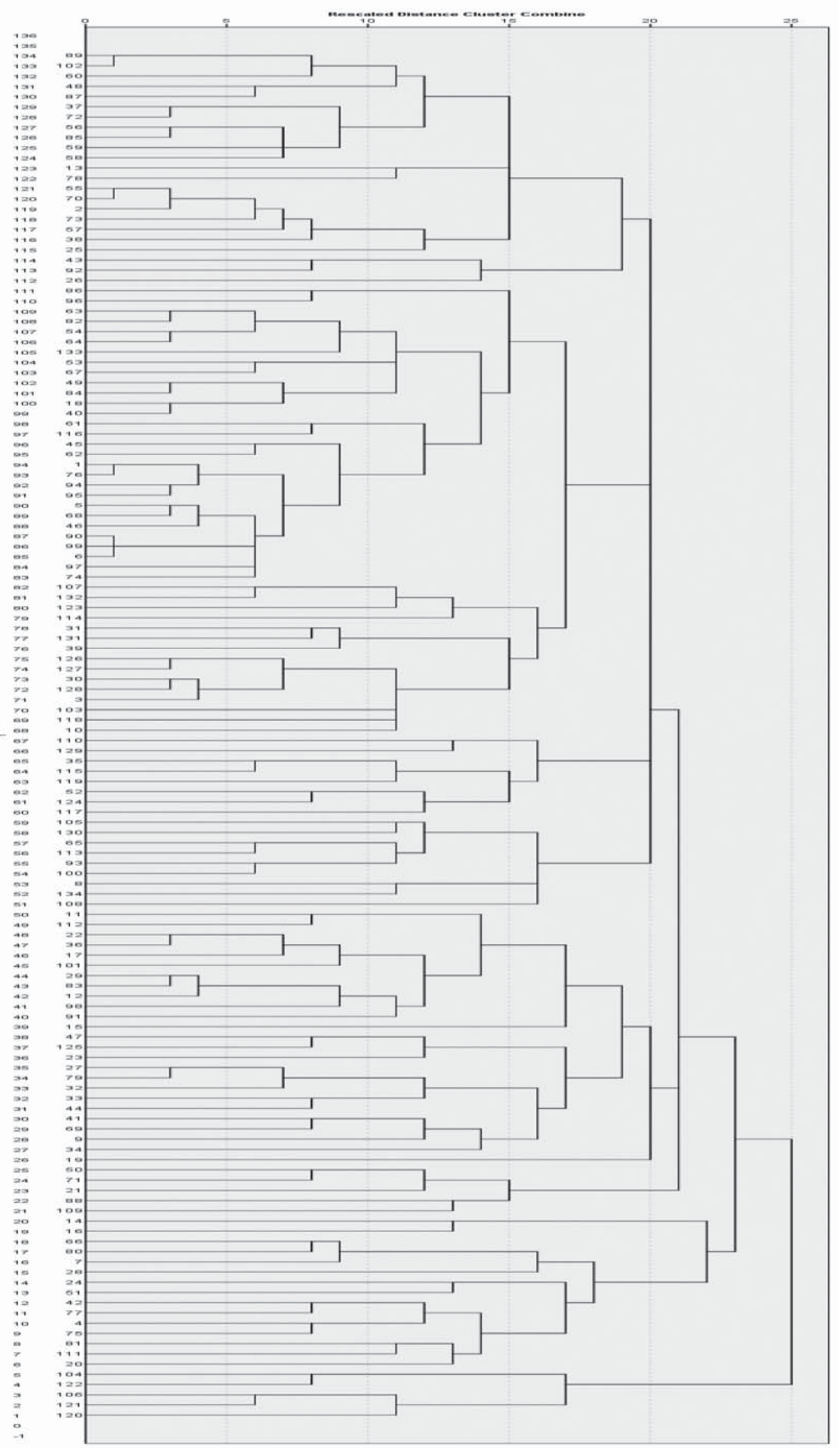




\section{TRAJECTORIES POLICIES AND ELECTORAL CHANCES: ANALYZING THE “GENDER” AMONG CANDIDATES 2010}

\section{Clara Maria de Oliveira Araújo and Doriam Borges}

This article presents the main results of a survey of candidates to Parliament, conducted within the research developed by the Consortium Bertha Lutz during the 2010 elections. It examines dimensions such as political trajectories and electoral strategies, resources and difficulties campaigns. The objective is to identify how gender is presented in possible intervening variables in these profiles. For this work we used two data sources: a survey sampling based on a structured questionnaire consisting questions regarding various individual and institutional dimensions, applied to Congress candidates in 14 states, and the data provided by applicants to the Superior Electoral Court . The statistical analysis for verification of hypotheses based on the Cluster Analysis. The results indicate that being male is associated with being or have already been parliamentary, be trying to re-election, have a reasonable time of political, owning militancy and have invested large resources in the election campaign. On the other hand, for a woman to have a campaign promising she should have a good political career and being inserted into social networking strategies. Based on the data, it is concluded that the strategy to achieve gender equality in Congress should follow these points: the parties, through consolidation of party experience, job positions public political forms of association and / or militancy and structuring networks or personal representative and, above all, availability of financial resources, or through personal networks and donations. The election process would therefore a result of a preceding filter even recruitment. Profiles elected, whether men or women, are similar, but as far as men are widely majority among the elect, we can say that these profiles are the result of a structure still marked by inequalities and values differentiated by gender.

KEYWORDS: gender; election; inequality; policy. 